Keywords:

Evaporator scaling, Aluminosilicates, uranates, Amorphous, Zeolite A, Sodalite, cancrinite

Retention Time: Permanent

\title{
Evaluation of the Incorporation of Uranium Into Sodium Aluminosilicate Phases (U).
}

Authors: Lawrence N. Oji and Adrienne L. Williams

Publication Date: November 20, 2002

Westinghouse Savannah River Company Savannah River Site

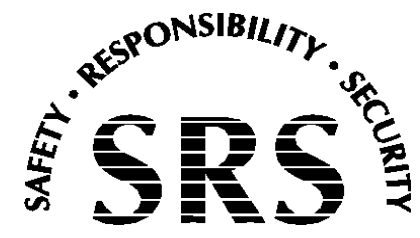

Aiken, SC 29808 
This document was prepared in conjunction with work accomplished under Contract No. DE-AC09-96SR18500 with the U. S. Department of Energy.

\section{DISCLAIMER}

This report was prepared as an account of work sponsored by an agency of the United States Government. Neither the United States Government nor any agency thereof, nor any of their employees, makes any warranty, express or implied, or assumes any legal liability or responsibility for the accuracy, completeness, or usefulness of any information, apparatus, product or process disclosed, or represents that its use would not infringe privately owned rights. Reference herein to any specific commercial product, process or service by trade name, trademark, manufacturer, or otherwise does not necessarily constitute or imply its endorsement, recommendation, or favoring by the United States Government or any agency thereof. The views and opinions of authors expressed herein do not necessarily state or reflect those of the United States Government or any agency thereof.

This report has been reproduced directly from the best available copy.

Available for sale to the public, in paper, from: U.S. Department of Commerce, National Technical Information Service, 5285 Port Royal Road, Springfield, VA 22161, phone: (800) 553-6847, fax: (703) 605-6900

email: orders@ntis.fedworld.gov

online ordering: http://www.ntis.gov/help/index.asp

Available electronically at http://www.osti.gov/bridge

Available for a processing fee to U.S. Department of Energy and its contractors, in paper, from: U.S. Department of Energy, Office of Scientific and Technical Information, P.O. Box 62, Oak Ridge, TN 37831-0062,

phone: (865)576-8401,

fax: (865)576-5728

email: $\underline{\text { reports@ adonis.osti.gov }}$ 


\section{Author(s)}

L. N. Oji, Waste Processing Technology

Date

A. L. Williams, Waste Processing Technology

Date

\section{DESIGN CHECK}

M. Duff, Waste Processing Technology

Date

\section{REVIEWS AND APPROVALS}

W. B. Van Pelt, Level 4 Manager, Waste Processing Technology

Date

R. E. Edwards, Manager, Process Engineering

-Date

W. L. Tamosaitis, Level 3 Manager Waste Processing Technology

Date 


\section{SUMMARY}

This report describes batch laboratory experiments performed to determine the relative amounts of uranium incorporated in aluminosilicate structures during synthesis. The findings summarized here are based on laboratory experiments, which involved the synthesis of sodium aluminosilicates (NAS) structures, amorphous, zeolites A and sodalite phases in the presence of depleted uranium and the analytical search for incorporated uranium in NAS internal structures after synthesis. These studies will support the basis for continued operation of evaporators at the Savannah River Site (SRS). The laboratory testing results indicated the following:

- Sodalite NAS materials synthesized are aggregates of materials with lots of internal cavities,

- Amorphous phase NAS look fluffy with magnification (cotton balls) with lots of internal structure and cavities,

- ZeoliteA materials formed have well-defined cubical geometric structures and contained 5-10\% sodalite impurities,

- Conditions that foster NAS precipitation is likely to foster uranium solid (uranium silicate, sodium uranates and uranium hydroxide) precipitation, so it is difficult to attribute problems with uranium accumulation to say just the formation of the aluminosilicates.

- Infrared spectral evidence shows that sodium uranate and other uranium solids are formed during the synthesis of these NAS phases in the presence of uranium,

- Uranium solids may be found on the surface and in the internal cavities of both sodalite and amorphous phases of NAS,

- Uranium solids may be physically trapped within the internal structures of both amorphous and sodalite phases,

- The order of total uranium loading during synthesis in the unwashed NAS solid phases are Sodalite>amorphous $>>$ Zeolite $\mathrm{A}$ and

- The order of measurable uranium, which could not be leached out with water and a chelating agent ( $\mathrm{Na}_{4}$ EDTA solution) and thus considered trapped inside the NAS phases, is Amorphous>sodalite>>Zeolite A.

For further studies, we recommend the following:

- Repeat synthesis and characterizations of all NAS materials in duplicate with detailed analytical characterization of NAS synthesis with and without uranium and evaluate the effect of uranium in NAS product yield.

- More studies should be done to investigate uranium solubility and solid phase formation in the presence of silicon and aluminum.

- Synthesize the aluminosilicates in the presence of U-235 in place of depleted uranium to enhance solid characterizations for incorporated uranium by neutron activation analysis.

- Complete NAS study with the synthesis of cancrinite with and without uranium. 


\section{TABLE OF CONTENTS}

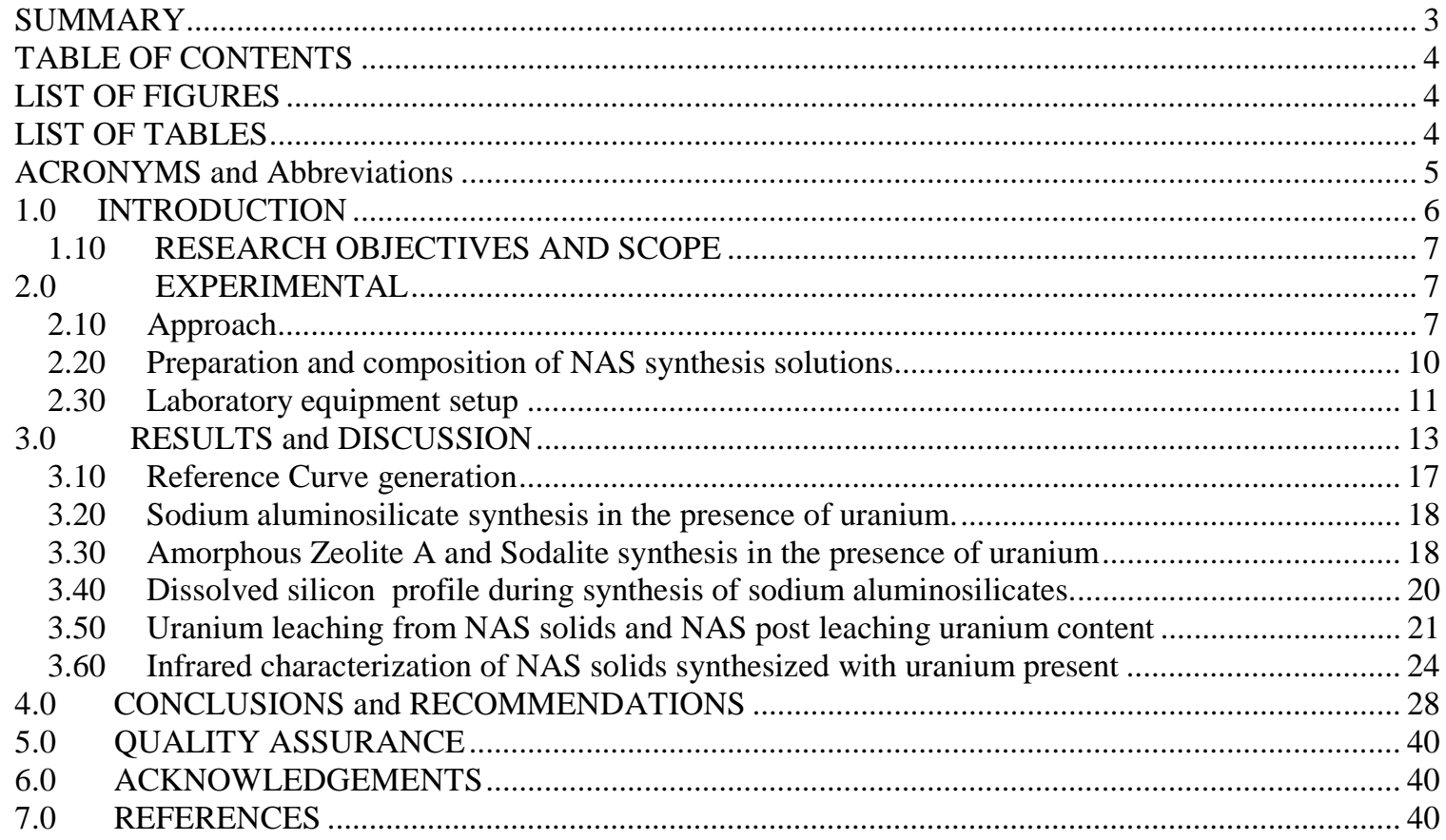

\section{LIST OF FIGURES}

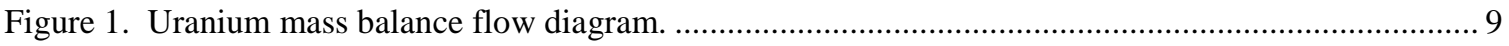

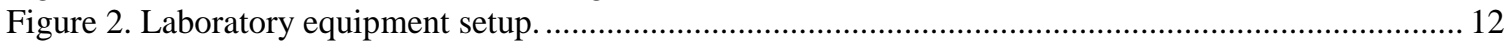

Figure 3. Confirmatory infrared spectra for the Aluminosilicates. ................................................... 15

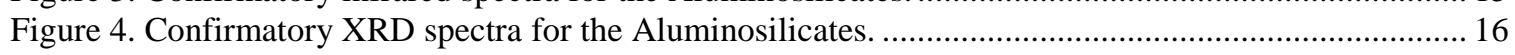

Figure 5. Overlay plot of amorphous and sodalite NAS reference curves at 50-mg/L uranium loading..... 17

Figure 6. Zeolite 6012 reference curves at 50-mg/L uranium loading.................................................. 18

Figure 7. Amorphous, zeolite A and sodalite synthesis in the presence of uranium. concentration profile. 19

Figure 8. Zeolite 6012 synthesis in the presence of uranium: Filtrate ................................................20

Figure 9. Silica depletion profile for amorphous, zeolite A and sodalite during synthesis in the presence.. 21

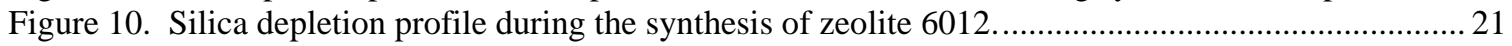

Figure 11. Amorphous, zeoliteA, zeolite A6012 and sodalite uranium ...............................................22

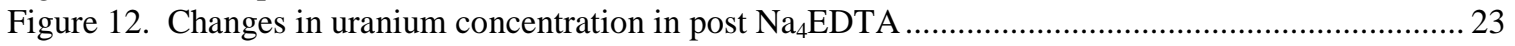

Figure 13. Overlay IR spectra for amorphous washes. Broad uranate absorption bands from 825 to 725 .. 26

Figure 14. Overlay IR spectra for sodalite wash. Uranate peaks at 864,829 and $720 \mathrm{~cm}^{-1}$ for unwashed .26

Figure 15. Overlay IR spectra for zeolite A (carbonate form) washes. No uranate peaks in the 900 to ...... 27

Figure 16. Overlay IR spectra for zeolite A 6012 (non-carbonate form) washes. Uranate peak present at. 27

\section{LIST OF TABLES}

Table 1. Summary of NAS product yields and uranium concentrations............................................ 24

Table 2. Main uranium solid IR bands in NAS solids. ........................................................... 25

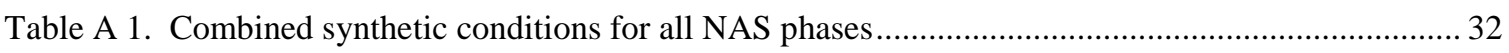

Table A 2. Final reagent concentrations for the synthesis of all NAS .............................................. 34 


\subsection{INTRODUCTION}

The High-Level Waste Tank Farms store and process high-level liquid wastes from a number of sources including $\mathrm{F}$ - and $\mathrm{H}$ - Area Canyons and a recycle stream from the Defense Waste Processing Facility (DWPF). The waste is relatively dilute as received and is concentrated in one of several evaporators to minimize the space required to store the waste. The concentrated waste is transferred to one of several concentrate receipt tanks for storage. Recently, the $2 \mathrm{H}$ Evaporator was shut down due to crystallization of sodium aluminosilicates (NAS), such as zeolite $\mathrm{A}\left(\mathrm{Na}_{6} \mathrm{Al}_{6} \mathrm{Si}_{6} \mathrm{O}_{24} \cdot \mathrm{nH}_{2} \mathrm{O}_{(\mathrm{s})}\right)$, sodalite $\left(\mathrm{Na}_{8}\left(\mathrm{AlSiO}_{4}\right)_{6} \cdot \mathrm{nH}_{2} \mathrm{O}_{(\mathrm{s})}\right)$ and cancrinite $\left(\mathrm{Na}_{8}\left(\mathrm{AlSiO}_{4}\right)_{6} \cdot \mathrm{nH}_{2} \mathrm{O}_{(\mathrm{s})}\right)$ in the evaporator and the precipitation of enriched uranium with the $\mathrm{NAS}^{1,2,3}$

The aluminosilicates, such as zeolites, are complex crystalline cages of tetrahedron oxygen atoms which encase either silicon or aluminum atoms. The oxygen atoms can be shared by only two tetrahedrons, and no two aluminum atoms can share the same oxygen atom. This restriction means that the $\mathrm{Al} / \mathrm{O}$ ratio is always equal to or less than one. The crystal structures that result are complex 3-D frameworks of aluminosilicates with precisely dimensioned channels (typically 2.5 to 8 Angstroms) and cages as in the case of sodalite running through them. These channels and cages enable the crystals to be selectively permeable to various gases and liquids as molecular sieves. As in the case of zeolites, for every aluminum atom in the unit cell made up of these tetrahedrons, there will be one free electron and hence negative charges. The negative charges are compensated for by incorporating cations (usually, but not limited to $\mathrm{Na}^{+}, \mathrm{K}^{+}, \mathrm{Ca}^{2+}$, $\mathrm{Mg}^{2+}$ ). These cations are not part of the actual framework of tetrahedrons, but reside at the internal channels. When these crystals absorb fluids in the channels, it is possible for one type of cation to be exchanged for another without affecting the electrical neutrality or crystal structure.

In the evaporator, several processes may contribute to the concentration of uranium. Uranium species, cations, solids, anion complexes etc, may be incorporated and concentrated in the NAS channels or cages as hosts as a result of uranium coprecipitation (adsorption, precipitation) during the formation of the aluminosilicates structures. Uranium may also be concentrated by adsorption on NAS surfaces, by precipitation with NAS minerals and by co-precipitation with the NAS minerals. Here we define the co-precipitation of uranium as the uptake of weighable amounts of uranium impurities (soluble or insoluble) into NAS phases during formation of NAS precipitates. The formation of NAS precipitates from supersaturated solutions of the reagents is extremely rapid. Under these conditions, uranium impurities may be unable to escape from the neighborhood of the crystal growth, so they become entrapped in pockets or crystal defects of the NAS particles.

This uranium and NAS interaction research is part of an ongoing effort to understand the mechanisms for uranium accumulation with sodium aluminosilicates in the $2 \mathrm{H}$ Evaporator. These studies will support the basis for continued operation of evaporators at SRS. This report documents experimental results conducted at the Savannah River Technology Center (SRTC) to examine uranium co-precipitation with sodium 
aluminosilicate structures sodalite, zeolite A, and amorphous phases during isothermal batch synthesis of these silicates in the presence of depleted uranium. This work complies with the work scope defined in the following plan: L. N. Oji, " Task Technical and Quality Assurance Plan for the Evaluation of Uranium Co-precipitation with Sodium Aluminosilicate Structures," WSRC-RP-2001-01096, Rev. 0 Dec. 13, 2001.

\subsection{RESEARCH OBJECTIVES AND SCOPE}

The principle objective of this study was to determine how much uranium, if any, is incorporated in NAS structures and to determine which of the silicate structures (sodalite, zeolite $\mathrm{A}$, and amorphous $\left(\mathrm{Na}_{12} \mathrm{Al}_{12} \mathrm{Si}_{12} \mathrm{O}_{48} \cdot \mathrm{nH}_{2} \mathrm{O}_{(\mathrm{s})}\right)$ phases) has the highest affinity for uranium as a result of co-precipitation. The information from this study will help High Level Waste (HLW) identify operational strategies to avoid or minimize formation of NAS forms with high affinity for uranium.

\subsection{EXPERIMENTAL}

\subsection{Approach}

Based on information and procedures provided by Dr. Mensa of the University of Southern Australia, aluminosilicate structures, sodalite, zeolite A and amorphous phases were synthesized. A description of Mensah's synthesis method for the aluminosilicates along with some modifications are summarized in Appendix A. The three silicate structures were washed and their identities were confirmed by X-ray diffraction (XRD) patterns, scanning electron microscopic (SEM) techniques and diffuse reflectance infrared-Fourier-transform (DRIFT) spectroscopic techniques.

To determine when uranium should be added during the aluminosilicate syntheses, precipitation timing studies (referred to as "reference" uranium curves) were performed with uranium and aluminum containing caustic salt solutions using the same experimental conditions (such as temperature) as those required for the individual NAS syntheses. A "reference" uranium curve for each of the NAS was generated without added silica in the reaction mixtures. The synthesis of each NAS was then repeated in the presence of $50 \mathrm{mg}$ uranium/L as summarized in flow diagram in Figure 1. The source of the depleted uranium used in this study was a stock solution of uranyl nitrate hexahydrate, which was originally provided by the Actinide Technology Section.

The sequence of analytical procedures used to account for uranium concentrations in solid NAS structures, by mass balance, in the unwashed NAS solids, reaction filtrate and structurally trapped uranium, if any, are summarized below in section 2.11 and Figure 1.

\subsection{Uranium mass balance summary.}

A. Initial uranium mass at time zero (50 mg),

B. Soluble uranium concentration in post NAS synthesis liqueur,

C. Uranium from DI water (distilled and de-ionized water) washed NAS solid cake (filtrate),

D. Uranium from $\mathrm{Na}_{4}$ EDTA wash of post DI washed and dried NAS solid

E. Uranium from acid digestion, post-Na $\mathrm{NaDTA}_{4}$ washed NAS solid. 
For the sake of simplicity, the sum of uranium from cases C, D and E above is assigned to be equal to $\alpha$ and uranium concentration in case B as equal to $\varphi$. Thus, $\tau=\alpha+\varphi$, Where $\tau$ is total mass of uranium used in synthesis $(50 \mathrm{mg}), \alpha$ is total mass of uranium trapped in each NAS solid (unleacheable uranium including surface bound uranium) and $\varphi$ is the uranium in each post-synthesis filtrate.

After the synthesis of each NAS solids in the presence of $50 \mathrm{mg}$ depleted uranium (step A above), the mass of uranium in the filtrate was determined (step B above). The quantitative difference in the mass of uranium between the initial $50 \mathrm{mg}$ uranium and the filtrate uranium concentration, is the amount of uranium in the solid fraction of the wet and unwashed NAS solid. Each NAS solid is now suspended in DI water and washed three times with DI water (step C above) and the filtrates analyzed for uranium content.

A known quantity of the air-dried solid is washed with $\mathrm{Na}_{4}$ EDTA solution to strip the NAS of all traces of surface bound uranium from the solid (step D) and air-dried to constant weight. A known amount of the air-dried $\mathrm{Na}_{4}$ EDTA washed sample was acid digested and analyzed for its uranium content (step E above).

Based on the above information uranium mass in the solid NAS (unwashed and washed parts) was calculated. The uranium detected in step E above, if any, is considered to be uranium structurally incorporated with that particular NAS form and sparingly soluble uranium forms. In summary, if there is no uranium remaining in the $\mathrm{Na}_{4} \mathrm{EDTA}$-washed NAS solid, then $(\mathrm{A}=\mathrm{B}+\mathrm{C}+\mathrm{D}$ or $\tau=\alpha+\varphi)$; $\mathrm{E}=0$. If $\mathrm{E}>0$, then $\mathrm{E}$ represents the amount of uranium that was resistant to removal using NaEDTA. The forms of uranium could be uranium remaining in E would be that which is structurally incorporated with NAS solids during synthesis and sparingly soluble uranium forms that are resistant to washing (i.e., dissolution) with DI water and $\mathrm{Na}_{4}$ EDTA.

From these information, the amount of uranium per gram of each of the three NAS from step D above is calculated and the comparative affinity for uranium by each of the NAS phasis determined by calculating the ratio of uranium trapped per gram of NAS product yield. The magnitude of the above ratio defines which of the three NAS phases has the greatest affinity for uranium during formation in the supersaturated liquer. Other complementary ways used for comparing the uranium affinity by each NAS phase includes the following:

- Characterization of the uranium "stripping efficiency" from each NAS phase, in order to determine the ease with which both DI water and the chelating agent can be used to easily remove all surface-bound uranium.

- The presence of infrared signatures for uranium solids, like sodium uranates, uranium silicates or hydroxides, in post DI water and $\mathrm{Na}_{4}$ EDTA washed solids.

- The local structure characterization of the uranium by the use of EXAFS technique ${ }^{4}$. 
WSRC-TR-2002-00527, Rev. 0

Page 9 of 41

November 20, 2002

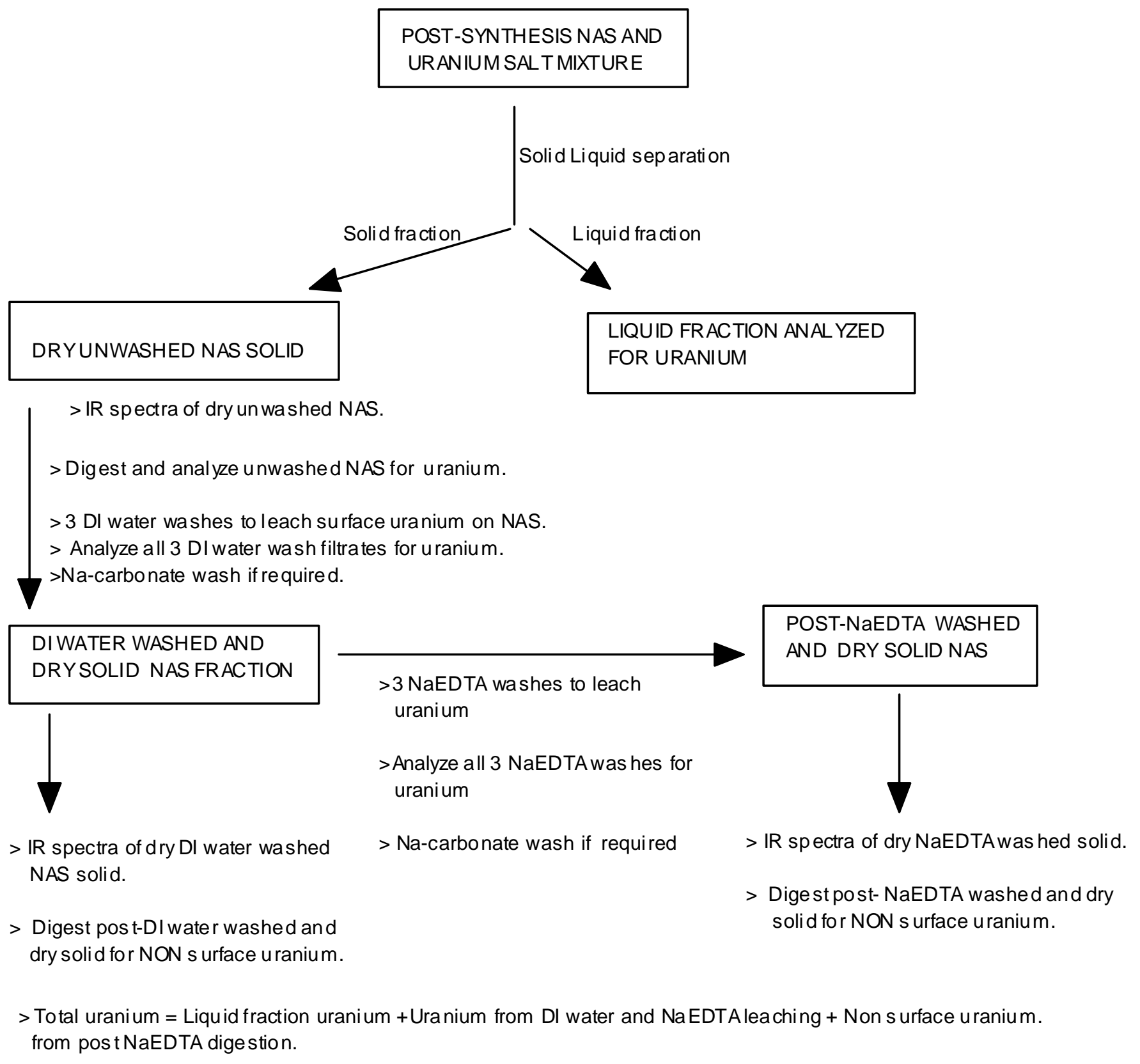

Figure 1. Uranium mass balance flow diagram.

2.12 Uranium reference curve

In a high caustic reaction environment, such as the one the aluminosilicates were synthesized in, the reaction kinetics for the formation of the aluminosilicates was 
expected to be quite different from that for the formation of uranium solids such as the sodium uranates $\left(\mathrm{Na}_{2} \mathrm{U}_{2} \mathrm{O}_{7}\right.$ and $\left.\mathrm{Na}_{2} \mathrm{UO}_{4}\right)$ and uranium silicates or hydroxides. Therefore, the reaction times for the formation of the silicates and the uranium solids had to be synchronized, if needed, to enhance the chances for uranium co-precipitation during the batch silicate synthesis in the presence of uranium. This approach would also ensure that this laboratory-based batch silicate synthesis does mimic the plant continuous process, which produces NAS containing uranium in the evaporator.

In the laboratory batch synthesis process for these silicates, we attempted to synchronize these two main reactions by first generating a uranium curve. From the uranium reaction profile we determined the definite time, $\tau_{\mathrm{u}}$, when uranium starts forming solids in the reaction mixture. The generation of each uranium reference curve involved the withholding of one of the reagents for NAS formation, in this case the silicate solution. Changes in ionic strength of the final reaction mixture, due to the withholding of silicate solution, were compensated for by adding equimolar concentration of sodium hydroxide. In these uranium reference curve reactions, the reactions were performed at the same reaction conditions already established for the formation of each NAS. No aluminosilicates are formed because of the absence of the silicate solution. In effect, only reactions leading to the formation of uranium solids were observed.

After determining this uranium time, $\tau_{\mathrm{u}}$, for each of the silicate synthesis, and if found significantly different from that of silicate synthesis without uranium, we were then to introduced the reagents into the reaction mixture in such a manner as to ensure simultaneous reactions for the formation of each NAS and the uranium solids.

In these synchronized batch reactions for the production of each NAS in the presence of uranium, all the reagents for NAS synthesis and uranium solids were expected to be initially present except, of course, the silicate solutions again. The required amounts of silicate solutions were to be injected into the reaction mixture at time, $\tau_{\mathrm{u}}$, corresponding to each NAS uranium reference curve. In this approach, both the formations of each NAS and uranium solid will start rapidly at the same time. Thus, on a reaction time scale, if we assume that the reaction for the formation of uranium solids is further along than that of the formation of NAS, this approach is simply a delay for the initiation of the reaction for the formation of each NAS.

\subsection{Preparation and composition of NAS synthesis solutions}

Research grade reagents were used throughout this study. The sodium aluminosilicate structures (amorphous, zeolite A and sodalite phases) were precipitated at various temperatures and reaction times from supersaturated caustic solutions as summarized in Appendix A (Tables A1 and A2).

Nitrated zeolite A is a metastable aluminosilicate and thus converts to sodalite with much ease. Sodium carbonate was initially used in the zeolite A synthesis, instead of the nitrate /nitrite anion compositions, in order to thermodynamically stabilize the zeolite A. We used the sodium carbonate in this synthesis as a structure directing agent to enhance the formation of zeolite A structures only. Because of the solubility of uranium in carbonated 
zeolite A formulation, synthesis modifications were made to produce stable zeolite A without sodium carbonate as a reaction ingredient (See modification and zeolite A types produced in Appendix A).

\subsection{Laboratory equipment setup}

The reaction vessel used for this isothermal aluminosilicate synthesis consisted of a oneliter stainless steel reaction vessel with a Pyrex ${ }^{\circledR}$ glass lid cover, which was machined to bear an o-ring grove (Figures 2). The domed glass lid, bearing an O-ring rubber seal, was secured onto the one-liter reaction vessel with an adjustable clamp assembly (Duran reaction clamp). The top portion or lid contained appropriate glass receptacles and ports for a reflux condenser unit, an electric stirrer shaft in the center, a thermocouple and a covered reagent/sampling port. The digital read-out overhead electric stirrer (Fisher) featured two variable speed ranges (60 to 500 and 240 to $2000 \mathrm{rpm}$ ). A 46-cm long plastic stirring shaft, rotating at $400 \pm 5 \mathrm{rpm}$, was used to keep the reactor contents well mixed. The synthesis conditions for each of the NAS phases were quite different and are summarized in Appendix A, Tables A1 and A2.

During NAS synthesis, the reaction vessel was placed in a heated circulator water bath equipped with a multi-step temperature controller and water re-circulator (Cole-Parmer). Since the synthesis mixtures involved the mixing of two solutions, all initially brought to the same temperature, two heated circulator water baths were used. 


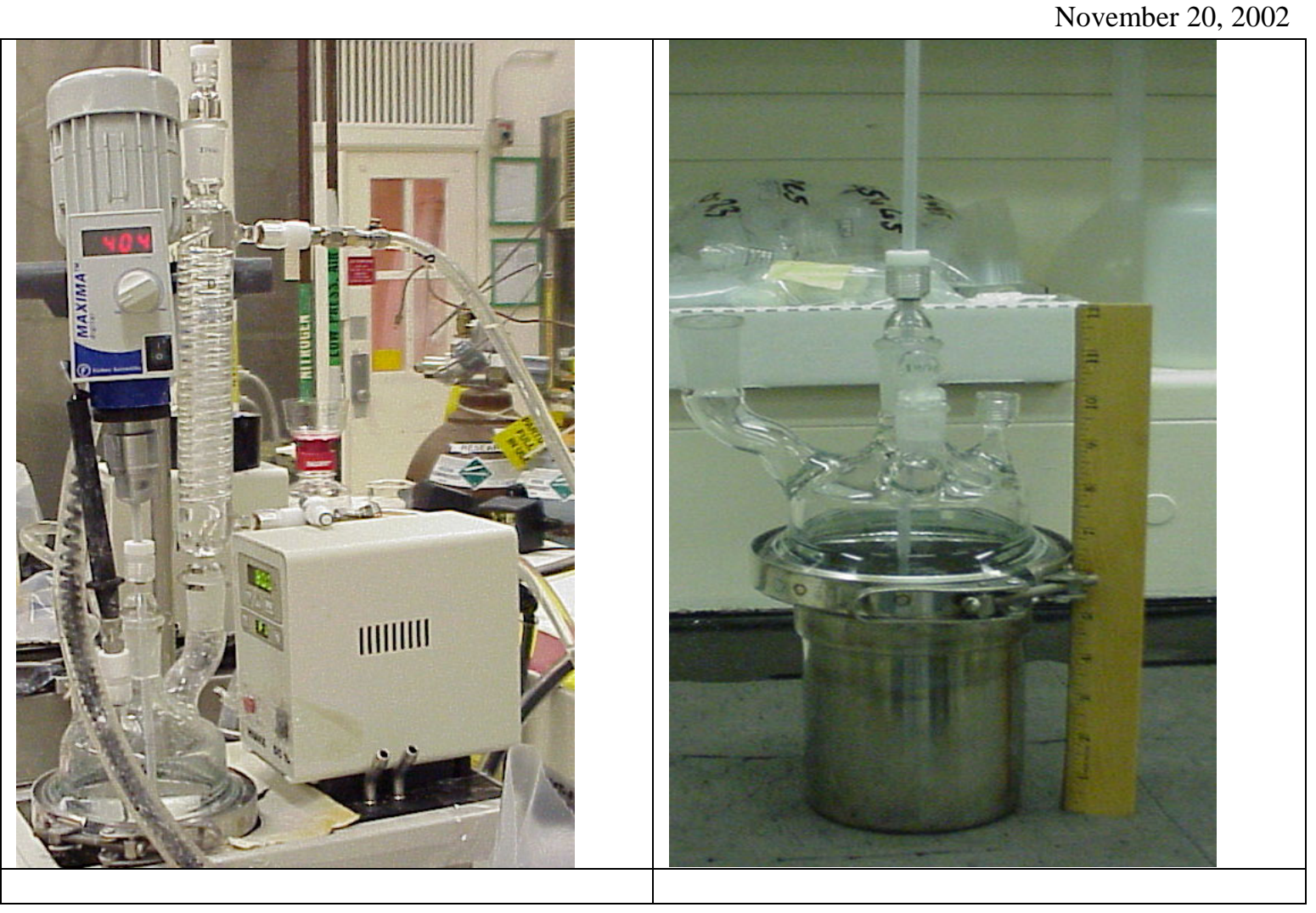

Figure 2. Laboratory equipment setup.

\subsection{Preparation of sodium aluminosilicates phases for characterization.}

After the synthesis of each aluminosilicate (Figure 1) the solid fraction was separated from the liquid fraction by filtration and the filtrate submitted for uranium and silicon analysis. The solid fraction from each NAS synthesized was vacuum dried to constant weight after several days in the hood at room temperature $\left(25 \pm 1^{\circ} \mathrm{C}\right)$.

A known weight of each dry solid fraction, usually 20-30 grams, was washed three times (three DI water leaching cycles) with a volume of DI water equivalent to a total of $50 \mathrm{ml}$ DI water per gram of dry solid NAS. For example, a 30-gram solid NAS will be washed with a total of $1500 \mathrm{ml}$ DI water at the end of the three water leaching cycles; that is $500 \mathrm{ml}$ DI water per leach cycle. During each wash cycle the solid is dissolved in the appropriate amount of liquid inside a 500-ml Teflon bottle, which was tightly capped and put into an orbital shaker (set at 200 rpm), for 2 hours. After each wash cycle, a solid liquid separation, using a 0.25micron Nylon membrane filter, was performed and the filtrate for that cycle saved for latter characterization for uranium content. During the second wash cycle, the solid fraction from the first wash was again suspended in DI water and the second wash cycle started and so on. At the end of the three DI water-washing cycles, 
three liquid fractions were submitted for uranium characterization and the water leached solid vacuum dried to constant weight. Fractions of the DI water leached and dried solid sample from each NAS synthesis was saved for the following characterizations, DRIFTS, acid digestion for uranium and silicon content, XRD and SEM in some cases.

The DI water washed and dried solids from each NAS material formed the starting material for the Na4EDTA and carbonate washes. From each DI water washed and dried solid, about 5 to 10 grams of the material was used for $\mathrm{Na}_{4}$ EDTA or in some cases sodium carbonate wash. The procedure described above for DI water uranium leaching from the solid was also used for all uranium leaching with $\mathrm{Na}_{4}$ EDTA or sodium carbonate solutions. The dry solids resulting from the three $\mathrm{Na}_{4}$ EDTA leaching was characterized (DRIFTS, acid digestion for uranium and silicon). The three-filtrate fractions from the leach cycles were also analyzed for uranium content.

Based on the uranium concentration from each of the washes involving DI water, $\mathrm{Na}_{4}$ EDTA, we obtained a plot of the percent uranium removed per leach cycle.

The uranium concentration in each solid material synthesized was also determined from acid digestion and subsequent analysis by ICP-MS and ICP-ES. The sum of uranium from the leaching cycles (DI water and $\mathrm{Na}_{4}$ EDTA) and acid digestion analysis together constitute the total uranium, $\alpha$, in the solid NAS phase under study.

\subsection{Synthesis and confirmation of aluminosilicate structures}

Figures 3 shows the infrared spectra of amorphous, zeolite A, zeolite A 6012 and sodalite phases, including the overlay spectra for specific wavelength regions, of the sodium aluminosilicates synthesized for this study. The XRD spectra of these NAS materials and other successful trial synthesis products are shown in Figure 4. Both the FT-IR and XRD spectra of all the NAS synthesized here matched those from the Australian team.

The synthesis of zeolite ${ }^{5}$ A posed a special problem because the original formulation contained sufficient amount of sodium carbonate, which prevented the complete evaluation of uranium incorporation during synthesis. As a result, we had to find other ways of synthesizing zeolite A without the use of sodium carbonate. During these trial preparations of zeolite A, we made another zeolite A material with oxalate anion in place of the carbonate anion used in the old formulation. We also made another type of zeolite A material based strictly on the old formulation with the carbonate reagent taken out (See Appendix A). The XRD spectra of these two new NAS materials confirmed that they were Zeolite A NAS phase (See Figure 4 below for the confirming XRD spectra). Based on the recommendations of the Australian team, we settled on a third form of zeolite A based on sodium silicate solution $\left(14 \% \mathrm{NaOH}\right.$ and $\left.27 \% \mathrm{SiO}_{2}\right)$ and sodium 
aluminate hydrate $\left(54 \% \mathrm{Al}_{2} \mathrm{O}_{3}\right)$ for the characterization of uranium incorporation with zeolite A. To distinguish this zeolite from the zeolite based on the old formulation, we designated it as Zeolite A 6012. The four digits, 6012, comes from the reaction temperature of $60{ }^{\circ} \mathrm{C}$ and duration of reaction (12 hours). Because a 12-hour reaction time for the synthesis of this zeolite A 6012 was unusually long we decided to see what the end product will be if the reaction time was reduced to 2 hours and temperature increased to $90{ }^{\circ} \mathrm{C}$ at equimolar aluminum and silica concentration $(1.7$ moles $)$. The final product was not a zeolite A material as expected, but rather sodalite. (See XRD, Figure 4).

In addition to the use of FT-IR and XRD techniques to confirm the successful synthesis of the NAS materials, we also obtained the SEM photographs of each material at different magnifications, as shown in Appendix B. 
WSRC-TR-2002-00527, Rev. 0

Page 15 of 41

November 20, 2002

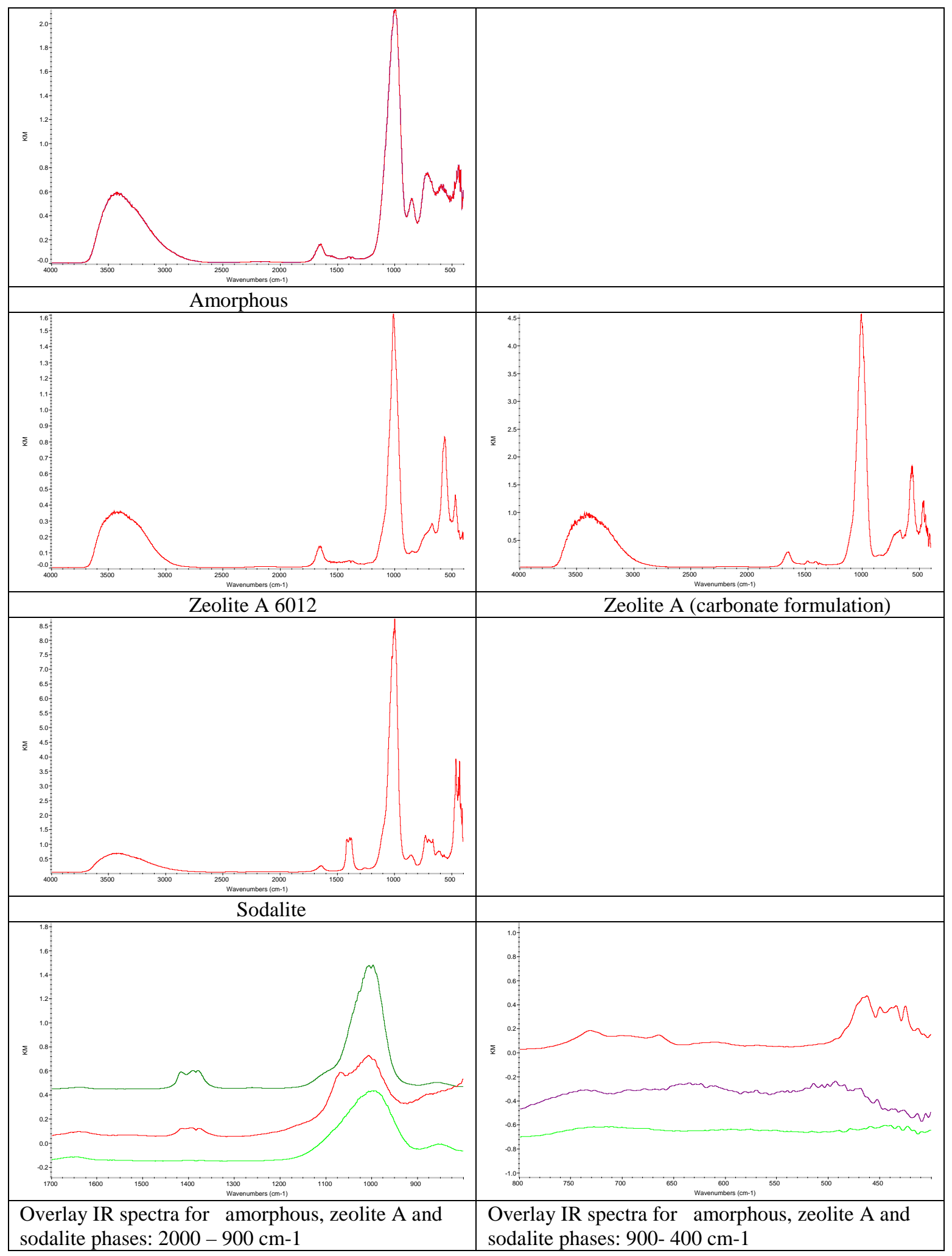

Figure 3. Confirmatory infrared spectra for the Aluminosilicates. 
WSRC-TR-2002-00527, Rev. 0

Page 16 of 41

November 20, 2002

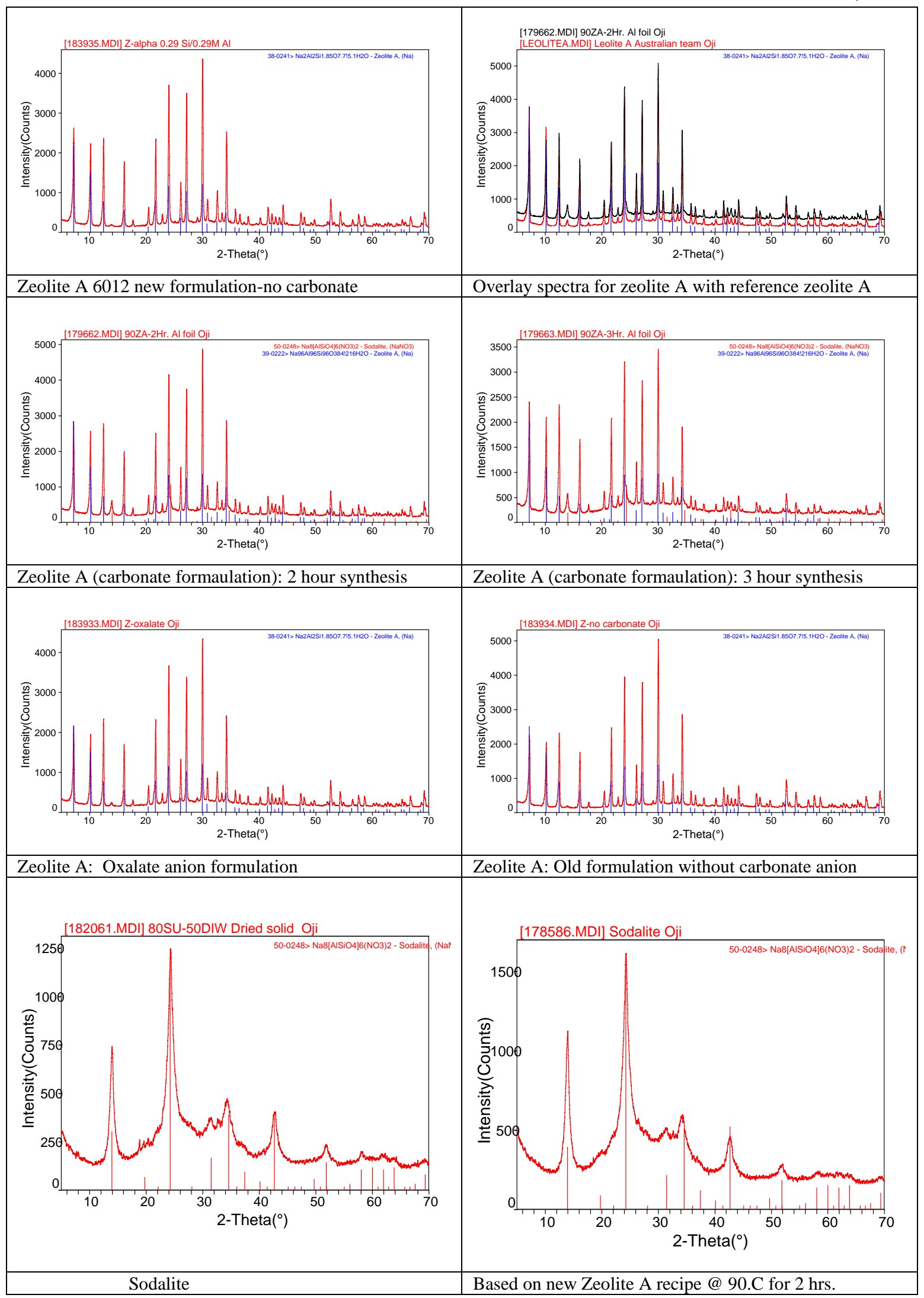

Figure 4. Confirmatory XRD spectra for the Aluminosilicates. 


\subsection{Reference Curve generation}

Figure 5 shows the overlay uranium reference curves for the amorphous and the sodalite reaction mixture. In both curves, the precipitation of uranium in the absence of silicon is complete within an hour. Therefore, since uranium precipitation starts at the instant when the amorphous and sodalite phases are formed, we can add all reagents, including uranium and silica at the beginning of the synthesis.

The uranium reference curve for the old zeolite A formulation based on sodium carbonate was not characterized because of problems associated with uranium and carbonate chemistry and its effects on uranium incorporation into zeolite A.

The uranium reference curve for zeolite A 6012 is shown if Figure 6.

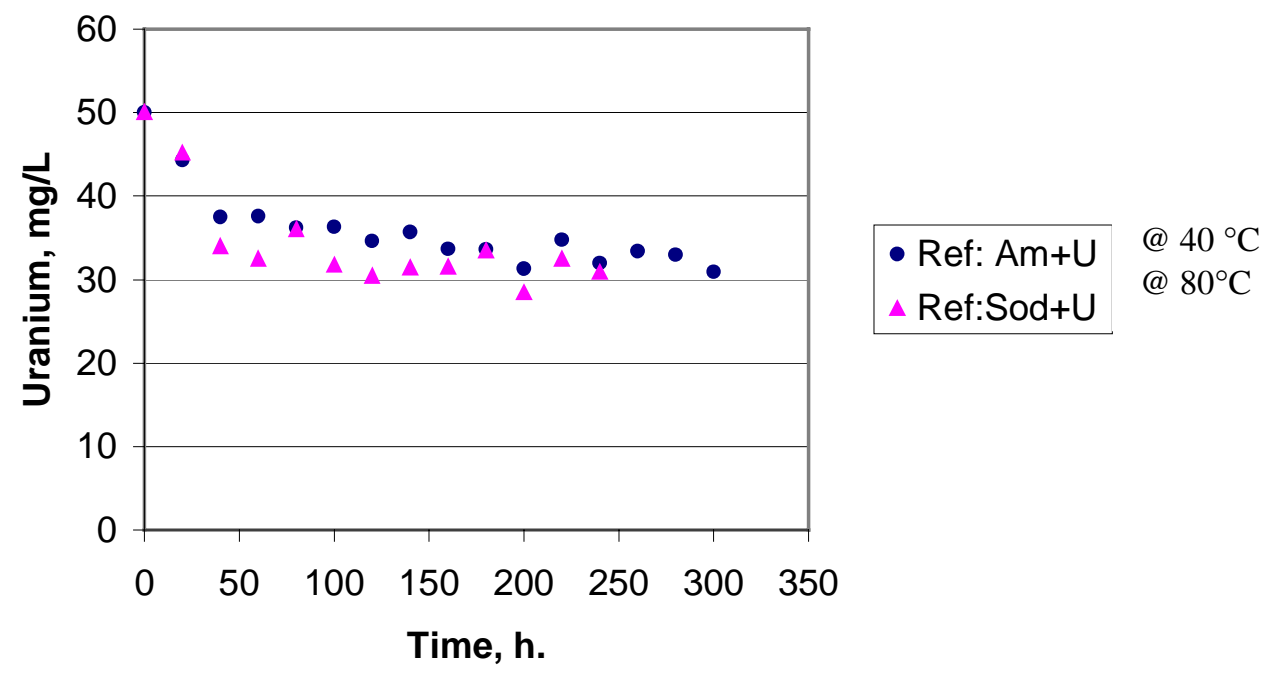

Figure 5. Overlay plot of amorphous and sodalite NAS reference curves at $50-\mathrm{mg} / \mathrm{L}$ uranium loading.

No significant evidence for uranium precipitation at the start of the reaction was observed. The reason for this behavior can be attributed to the reagent solution composition for the new zeolite formulation. At this caustic composition and uranium composition of $50 \mathrm{mg} / \mathrm{L}$, uranium will not precipitate out of solution because of solubility limits (Uranium is probably not supersaturated in this particular solution). At higher uranium concentration, say above $75 \mathrm{mg} / \mathrm{L}$, we expect uranium to precipitate out of this caustic solution. However, we went ahead and started the zeolite A synthesis in the presence of uranium by adding all 
the reagents, which includes uranium and silica at the beginning of the synthesis as we did before.

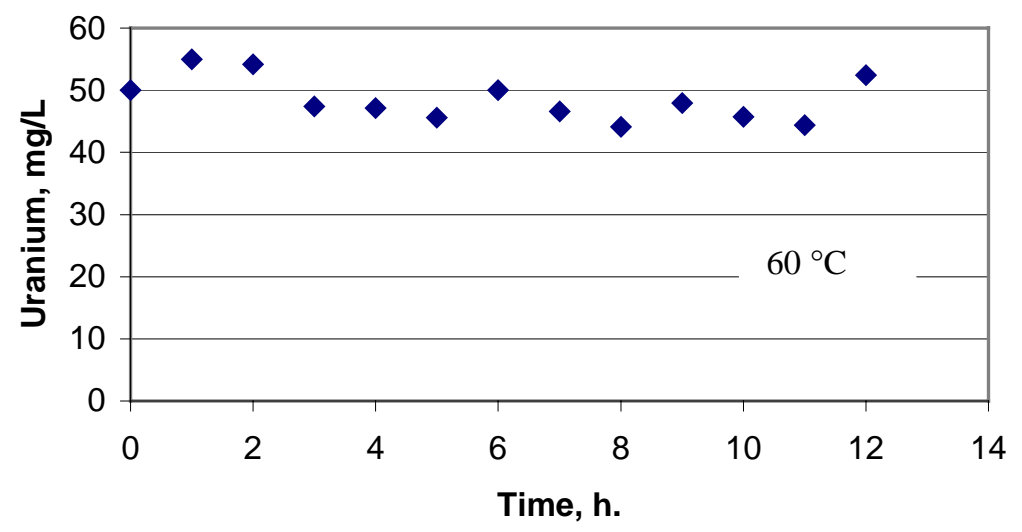

Figure 6. Zeolite 6012 reference curves at 50-mg/L uranium loading.

\subsection{Sodium aluminosilicate synthesis in the presence of uranium.}

The three NAS materials were each synthesized in the presence of $50 \mathrm{mg}$ uranium per liter of NAS synthesis reagent solution of supersaturated caustic solutions. The choice of $50 \mathrm{mg} / \mathrm{L}$ uranium concentration was based on the fact that we needed an NAS synthetic environment, saturated with uranium to ensure a greater probability of forming detectable uranium solids during synthesis and the generation of uranium reference curve. During the synthesis of the three NAS materials in the presence of uranium, samples were collected at selected intervals, which were based on the duration of each synthesis.

\subsection{Amorphous Zeolite A and Sodalite synthesis in the presence of uranium}

The overlay uranium concentration profile during the synthesis of these NAS materials is shown in Figure 7. The overlay plot in Figure 7 includes the synthesis of zeolite $\mathrm{A}$ at $90{ }^{\circ} \mathrm{C}$ for 2 hours using the old carbonate based formulation (See Appendix A), while the plot for zeolite A 6012 (new formulation) is shown in Figure 8. The uranium concentration changes during the synthesis of zeolite A (old formulation) in Figure 7, initially shows a decrease in uranium within the first 40 minutes into the reaction (from $50 \mathrm{mg} / \mathrm{L}$ down to $38 \mathrm{mg} / \mathrm{L})$. After this sharp decrease in soluble uranium the concentration increased to an equilibrium value of about $47 \mathrm{mg} / \mathrm{L}$. If we assume that this change in uranium concentration is not an analytical artifact, this changes in concentration will seam to suggest that precipitated uranium, during the course of 
the reaction re-dissolved and went back into solution. At the end of the synthesis for zeolite A (old formulation) the uranium concentration was $46.90 \mathrm{mg} / \mathrm{L}$.

From Figure 8 plot for the new zeolite A formulation (zeolite A 6012), there is no significant uranium precipitation during the synthesis period. The concentration of soluble uranium dropped down to only $48.4 \mathrm{mg} / \mathrm{L}$ at the end of the synthesis.

From the overlay plots in Figure 7 for the synthesis of both amorphous and sodalite NAS phases, there is a distinct loss of soluble uranium from the two reaction mixtures. At the end of the amorphous phase synthesis, the soluble uranium mass was $12.96 \mathrm{mg} / \mathrm{L}$, meaning that about $37 \mathrm{mg}$ of the uranium was held in some fashion on or in the solid amorphous solid matrix. Similarly, at the end of the sodalite phase synthesis the soluble uranium concentration was 12.0 $\mathrm{mg} / \mathrm{L}$, which corresponds to about $40 \mathrm{mg}$ of uranium trapped in the sodalite solid matrix. Overall, the sodalite synthesis showed the largest uranium drop compared to the synthesis of the other NAS materials. In less than 10 minutes into the reaction for the sodalite synthesis in the presence of uranium, the soluble uranium mass had dropped below the average uranium concentration of $11.3 \mathrm{mg}$, down to about $5 \mathrm{mg}$ and then started creeping up again with time. This may indicate a redissolving of the insoluble uranium formed during the initial phase of the synthesis.

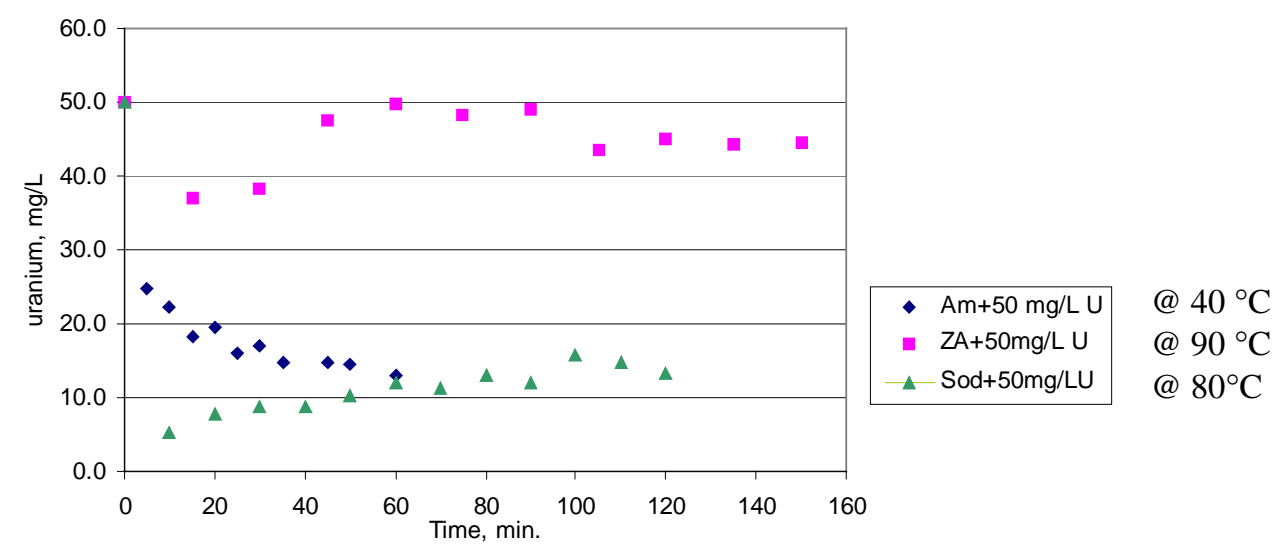

Figure 7. Amorphous, zeolite A and sodalite synthesis in the presence of uranium. Filtrate uranium concentration profile. 


\subsection{Dissolved silicon profile during synthesis of sodium aluminosilicates.}

Figure 9 shows the overlay plot for the disappearance of soluble silicon in the reaction mixture during the synthesis of amorphous, zeolite A (old formulation) and soldalite phases in the presence of uranium. A similar plot is shown in Figure 10 for the synthesis of zeolite A 6012. Note that the two figures could not be combined because of significant differences in synthesis time duration; two hours at $90^{\circ} \mathrm{C}$ for the old formulation and 12 hours at $60{ }^{\circ} \mathrm{C}$ for the new formulation.

The overlay plots show that in less than ten minutes into the reaction for the sodalite formation, the soluble silicon in the reaction mixture drops down to an equilibrium concentration. The time for soluble silicon concentration in the synthesis mixture to drop to the equilibrium levels for the Zeolite A (old formulation) and amorphous phase, are respectively, 50 and 40 minutes.

From Figures 7 and 9, we see that both silicon and uranium are depleted from the reaction mixture during the synthesis of both the amorphous and sodalite phases. There is depletion of silicon but not much of uranium from both zeolite A and zeolite A 6012 reaction mixtures (Figures 7, 8, 9 and 10.

Due to analytical cost and schedule pressures, the silicon depletion plots for the NAS synthesis without uranium additives was not performed for comparison.

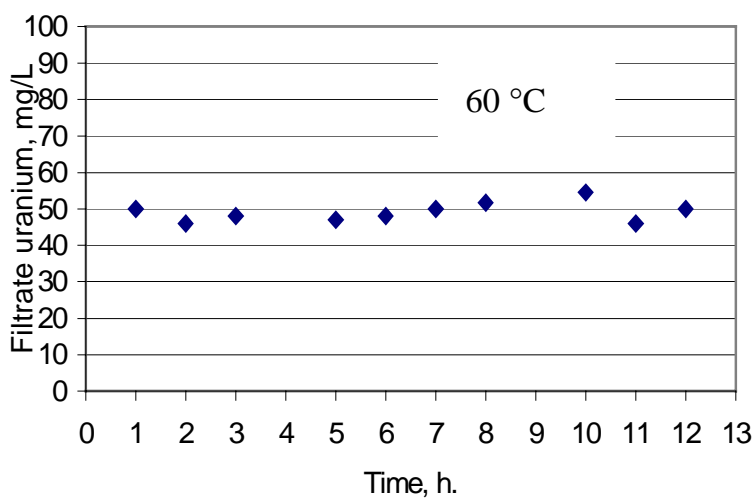

Figure 8. Zeolite 6012 synthesis in the presence of uranium: Filtrate uranium concentration profile. 


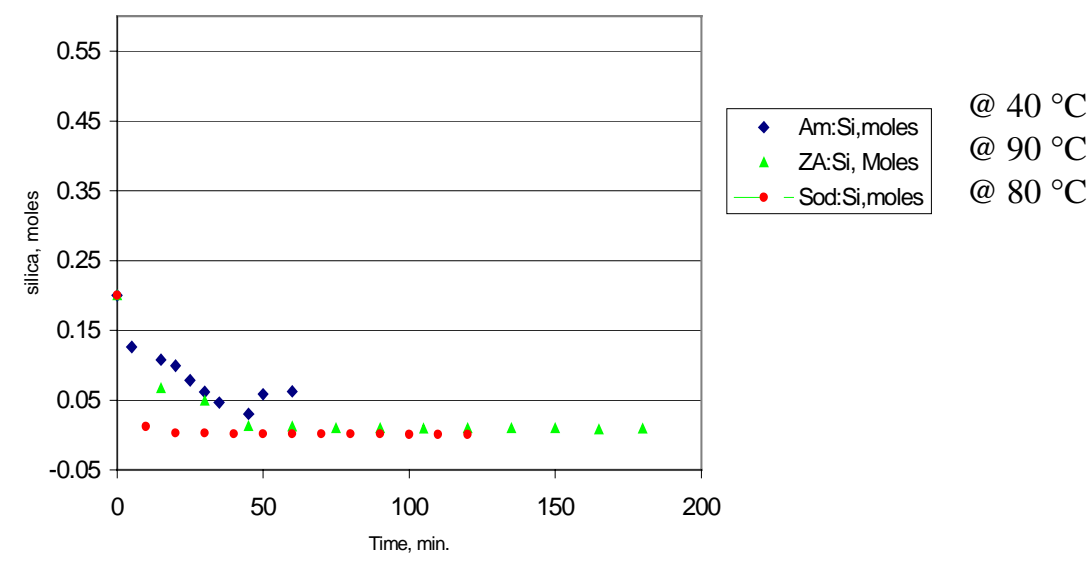

Figure 9. Silica depletion profile for amorphous, zeolite A and sodalite during synthesis in the presence of uranium.

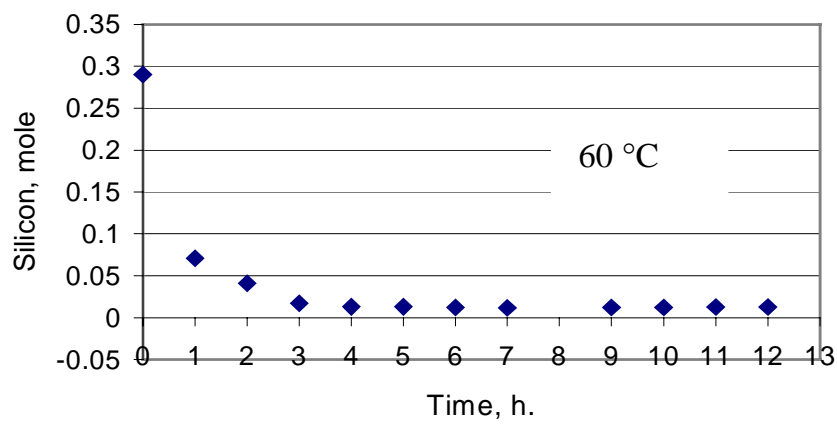

Figure 10. Silica depletion profile during the synthesis of zeolite 6012.

\subsection{Uranium leaching from NAS solids and NAS post leaching uranium content}

Figures 11 and 12 show, respectively, the percent uranium leached or removed from the surface of amorphous, zeolite A, zeolite 6012 and sodalite phases bearing uranium solids with DI water and $\mathrm{Na}_{4}$ EDTA solutions. The successive washing or leaching cycles with these solutions was performed three times with each NAS solid as described earlier.

Each solid NAS was first leached three times with DI water and the recovered dry solid material leached with $\mathrm{Na}_{4}$ EDTA to remove all the remaining surface 
bound uranium solids which could not be leached by water. After these two washes, we conclude that any uranium recovered from the solid NAS by acid digestion is uranium incorporated in the NAS matrix during synthesis.

The leaching of uranium with water from all the NAS materials with the exception of the amorphous phase, Figure 11, shows that only 5 to $20 \%$ of the surface uranium were removed. After the second wash of the amorphous phase with DI water, the percent uranium leached thereafter stayed fairly constant.

The other NAS materials, again, with the exception of the amorphous phase, after leaching with water and $\mathrm{Na}_{4}$ EDTA three times each, resulted in the removal of most of the surface bound uranium (Figure 12). The asymptotic nature of both the water and $\mathrm{Na}_{4}$ EDTA leaching curves for amorphous phase, especially after the second washes, indicates that all the surface bound uranium are not easily removed with these two leacheates (See Figures 11, 12 and 13). As a result, further leaching was performed with $0.4 \mathrm{M}$ solution of sodium carbonate. This solution still did not remove all the surface uranium as seen on infrared spectra on the post sodium carbonate washed solid (See IR spectra of amorphous solid washed with leaching solutions, Figure 13).

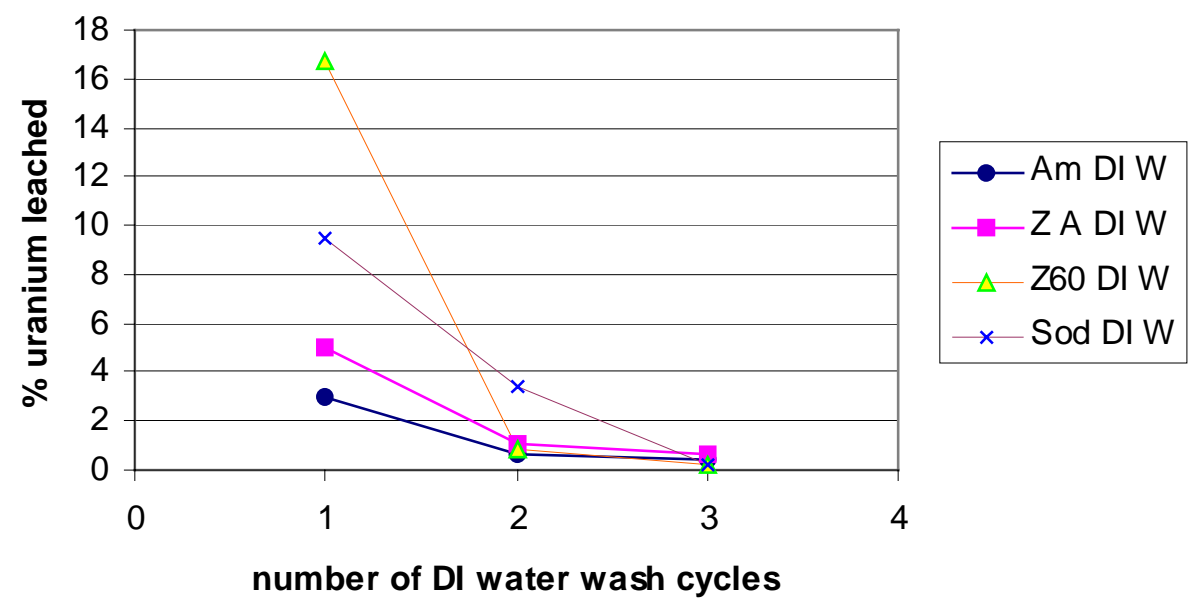

Figure 11. Amorphous, zeoliteA, zeolite A6012 and sodalite uranium concentration changes with number of distilled water wash cycles. Only a 5-20\% of the uranium removed with DI water washes. 


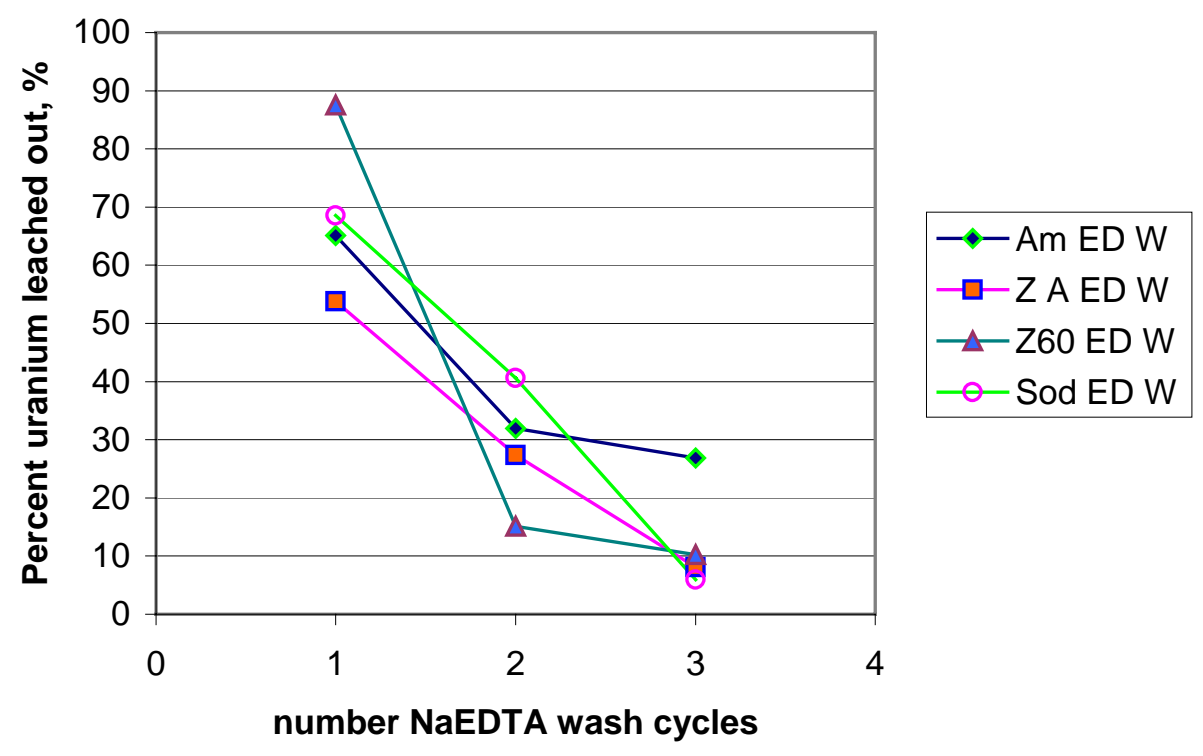

Figure 12. Changes in uranium concentration in post Na $\mathbf{E D T A}$ leaching of amorphous, zeolite A, zeolite A6012 and sodalite NAS solids.

Any uranium solids bound on the surfaces of the two forms of zeolites synthesized in the presence of uranium were easily removed after washing with water and $\mathrm{Na}_{4}$ EDTA.

As earlier mentioned, any uranium recovered from acid digestion of NAS solids from which surface bound uranium have been leached with DI water and $\mathrm{Na}_{4}$ EDTA for several hours in an orbital shaker, is considered to be trapped or incorporated uranium. Analytical digestion results from post $\mathrm{Na}_{4} \mathrm{EDTA}$ leached solids are summarized in Table 1 . Table 1 data contains the unwashed product yield for each NAS material synthesized (column 2), total uranium content in unwashed solid NAS fraction (column 3), DI water washed and dried NAS solid fraction yield (column 4), total incorporated uranium for each NAS from post leaching digestions (column 5) and the ratio of total uranium in unwashed NAS solid fraction per gram of unwashed NAS solid fraction yield.

The amorphous NAS phase has the largest product yield followed by the two different forms of zeolite A phases. On the other hand, the sodalite phase, with the lowest product yield, showed the most uranium loading for the unwashed solid fraction followed by the amorphous phase. The two zeolites phases did not 
trap significant amounts of uranium. The ratio of incorporated uranium per gram of unwashed NAS product yield for the amorphous phase (0.116) is higher than that for the sodalite phase $(0.075)$. This same ratio for the zeolite phases is significantly lower $(\approx 0.02)$. Thus, the uranium trapped in zeolite A phases, if any, is not significant and depends on the amount of sodalite impurity in the zeolite A phase.

All the zeolite A phases synthesized in this study contained various proportions of sodalite materials as an impurity, although XRD and infrared characterizations in most cases confirmed the existence of only the zeolite A phase. From SEM microphotos of the zeolites, between 5 to $10 \%$ of the materials was sodalite (See Appendix B). We estimated the level of sodalite impurity from SEM microphotos by visually counting the number of visible sodalite aggregates, which looked spherical or circular in appearance and the number of cubical zeolite A phases. From the number of spherical sodalite aggregates and cubical zeolite phases we calculated the total surface area for each materials. The ratio of the total surface areas was used as an estimate of the level of sodalite impurities.

Table 1. Summary of NAS product yields and uranium concentrations.

\begin{tabular}{|l|l|l|l|l|l|}
\hline & $\begin{array}{l}\text { NAS Yield, g } \\
\text { (unwashed solid) } \\
\text { g }\end{array}$ & $\begin{array}{l}\text { Uranium in } \\
\text { unwashed NAS } \\
\text { solid fraction, mg }\end{array}$ & $\begin{array}{l}\text { Post-DI water } \\
\text { Washed NAS } \\
\text { solid weight, g }\end{array}$ & $\begin{array}{l}\text { Incorporated } \\
\text { uranium , mg }\end{array}$ & $\begin{array}{l}\text { Total uranium in solid } \\
\text { phase/ NAS solid + salt } \\
\text { (mgU/g NAS) }\end{array}$ \\
\hline & & & & & \\
\hline Amorphous & 182.0 & $37.04(35.14)^{*}$ & 101.75 & 21.10 & 0.20 \\
\hline Zeolite A & 74.0 & 3.1 & 43.53 & 1.6 & 0.04 \\
\hline Zeolite A 6012 & 93.5 & 4.59 & 62.68 & 1.72 & 0.05 \\
\hline Sodalite & 63.5 & $40(38)^{*}$ & 34.56 & 4.79 & 0.63 \\
\hline
\end{tabular}

* Uranium concentrations based on subtractions in Figure 7.

3.60 Infrared characterization of NAS solids synthesized with uranium present The overlay spectra in Figures 13,14,15 and 16 show, respectively, the infrared spectra of unwashed and washed solids from the amorphous, sodalite, zeolites A (carbonate form) and zeolites A 6012 solids. All these unwashed NAS solids, with the exception of carbonated zeolite A material, showed infrared bands which can be assigned to uranium solids ${ }^{6,7,8}$ such as uranium silicates, uranium hydroxides and sodium uranates (di-and mono-uranates). The zeolite A (carbonated form), unlike the zeolite A 6012 (non-carbonate formulation), showed no infrared bands for uranium solids.

The unwashed amorphous phase from synthesis with uranium showed a broad infrared absorption band from about 850 to $725 \mathrm{~cm}^{-1}$ with the main peak centered at $801 \mathrm{~cm}^{-1}$. There are other subtraction infrared bands at 668 and $565 \mathrm{~cm}^{-1}$ (Figure 13 and Table 2). As earlier mentioned, the washing of the solid amorphous solid with DI water and $\mathrm{Na}_{4}$ EDTA was followed with an extra wash 
WSRC-TR-2002-00527, Rev. 0

Page 25 of 41

November 20, 2002

with sodium carbonate because the uranium bands persisted after leaching with water and $\mathrm{Na}_{4}$ EDTA only. The final leaching with sodium carbonate still failed to remove all the uranium solid bands.

Two major infrared bands corresponding to uranium solids at 865 and $829 \mathrm{~cm}^{-1}$ were observed with the unwashed uranium loaded sodalite. Other minor peaks are observed at $720 \mathrm{~cm}^{-1}$ Figure 14 and Table 2.

The zeolite A 6012 (non-carbonate formulation) had two infrared bands for uranium solids at 865 and $565 \mathrm{~cm}^{-1}$ Figure 16 and Table 2.

Table 2. Main uranium solid IR bands ${ }^{1}$ in NAS solids.

\begin{tabular}{|l|l|l|l|l|}
\hline Leacheate & Amorphous & Zeolite A & Zeolite A 6012 & Sodalite \\
\hline Unwashed NAS & & & & \\
\hline & $\begin{array}{l}801,668 \text { and } 558 \\
\mathrm{~cm}^{-1}\end{array}$ & None & 865 and $565 \mathrm{~cm}^{-1}$ & 865,829 and $720 \mathrm{~cm}^{-1}$ \\
\hline DI water/Na4EDTA & Broad band & None & None & None \\
\hline & & & & \\
\hline Carbonate & Broad band & NA & NA & NA \\
\hline
\end{tabular}

\footnotetext{
${ }^{1}$ Sodium uranate reference IR spectra bands: 827, 568 and $486 \mathrm{~cm}^{-1}$ for $\mathrm{Na}_{2} \mathrm{U}_{2} \mathrm{O}_{7}$ and 809,518 and $453 \mathrm{~cm}^{-1}$ for $\mathrm{Na}_{2} \mathrm{UO}_{4}$. IR bands for uranium silicates and uranium hydroxides occur between 800 and 900 $\mathrm{cm}^{-1}$, too.
} 
WSRC-TR-2002-00527, Rev. 0

Page 26 of 41

November 20, 2002

$$
\begin{aligned}
& 1=\text { IR spectra w/o uranium loading } \\
& 2=\text { NAS IR spectra with uranium } \\
& 3=\text { DI water washed IR spectra of NAS } \\
& 4=\mathrm{Na}_{4} \text { EDTA washed IR spectra of NAS } \\
& 5=\text { Sod. Carbonate washed IR spectra of NAS }
\end{aligned}
$$

Uranate band at 801,668 and $565 \mathrm{~cm}^{-1}$
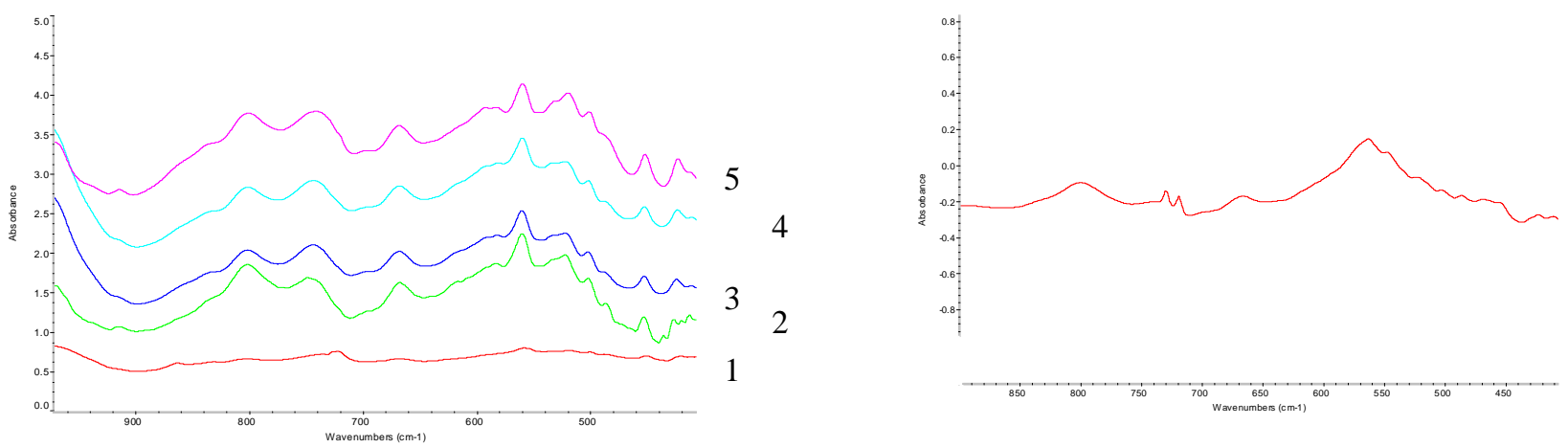

Figure 13. Overlay IR spectra for amorphous washes. Broad uranate absorption bands from 825 to $725 \mathrm{~cm}^{-1}$ still visible after all washes.

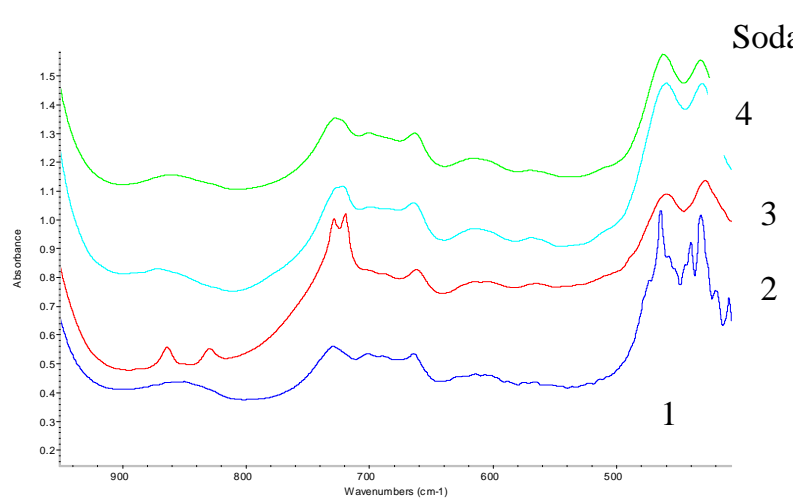

Sodalite uranate peaks @ 865, 829 and $720 \mathrm{~cm}^{-1}$

4

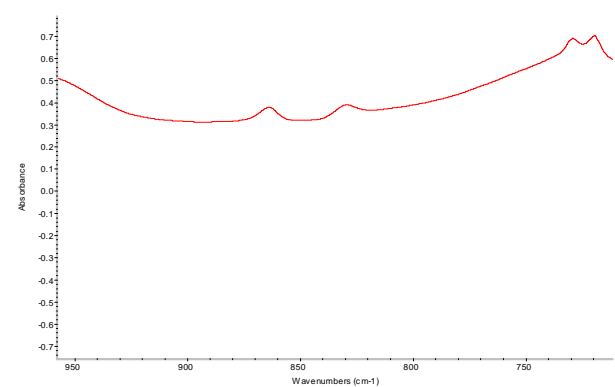

Figure 14. Overlay IR spectra for sodalite wash. Uranate peaks at 864, 829 and $720 \mathrm{~cm}^{-1}$ for unwashed sodalite and no uranate bands after washes. 
WSRC-TR-2002-00527, Rev. 0

Page 27 of 41

November 20, 2002

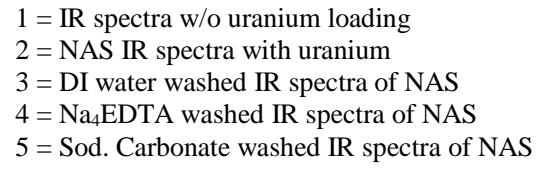

Zeolite A-carbonate: No uranium peaks between $900-500 \mathrm{~cm}^{-1}$
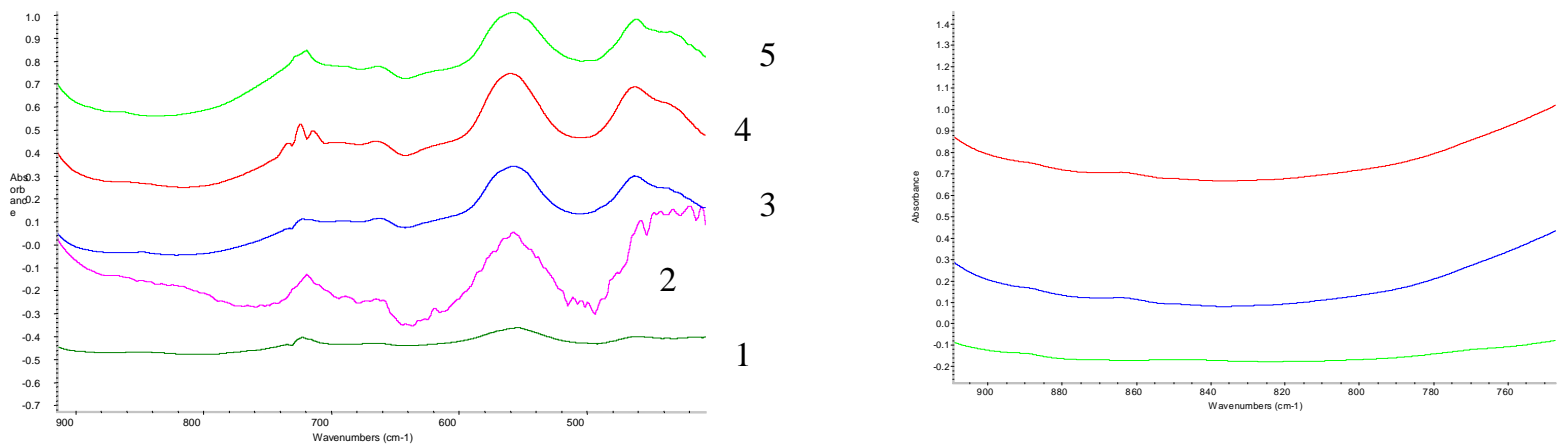

Figure 15. Overlay IR spectra for zeolite A (carbonate form) washes. No uranate peaks in the 900 to $800 \mathrm{~cm}^{-1}$ region.
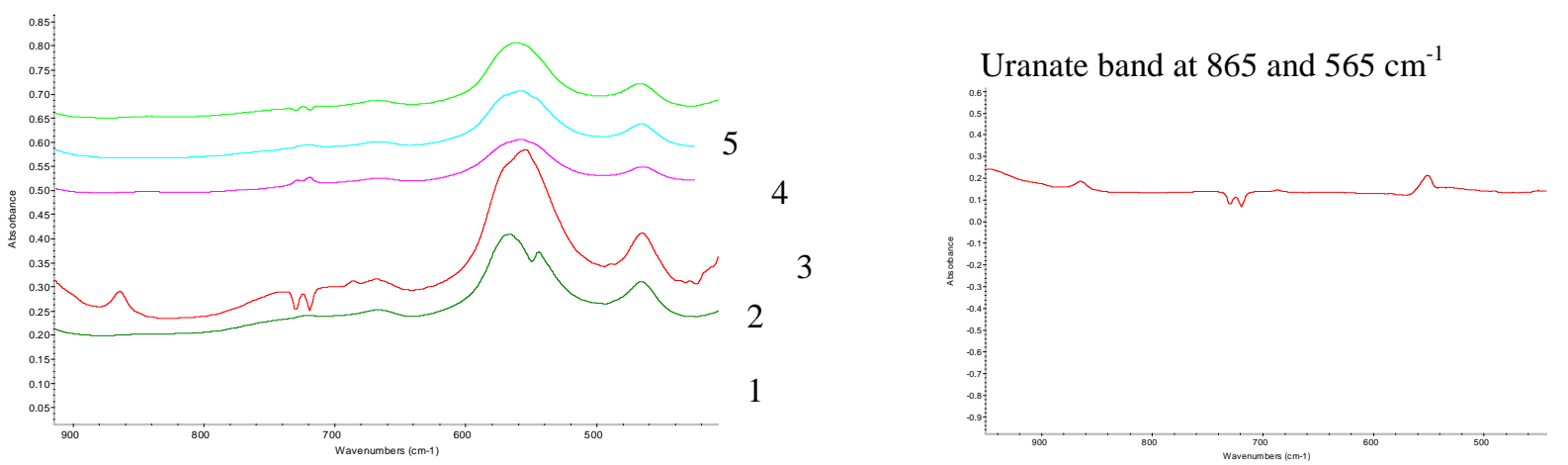

Figure 16. Overlay IR spectra for zeolite A 6012 (non-carbonate form) washes. Uranate peak present at 865 and $565 \mathrm{~cm}^{-1}$ for the unwashed zeolite 6012 and no uranate peaks after washes. 


\subsection{CONCLUSIONS and RECOMMENDATIONS}

We have used a batch laboratory testing to evaluate the potential for the incorporation of uranium into sodium aluminosilicate structures during synthesis. These experiments were designed to provide insight into the possibility of physically or chemically trapping of uranium as solids or otherwise into NAS structures during synthesis in a supersaturated and high caustic environment. The following conclusions are based on the observations and results obtained in the laboratory-scale investigations detailed above:

- Sodalite NAS materials synthesized are aggregates of materials with lots of internal cavities,

- Amorphous phase NAS look fluffy with magnification (cotton balls) with lots of internal structure and cavities,

- ZeoliteA materials formed have well-defined cubical geometric structures and contained 5-10\% sodalite impurities,

- Conditions that foster NAS precipitation are likely to foster uranium solid (uranium silicate, sodium uranates and uranium hydroxide) precipitation, so it is difficult to attribute problems with uranium accumulation to say just the formation of the aluminosilicates,

- Infrared spectral evidence shows that sodium uranate and other uranium solids are formed during the synthesis of these NAS phases in the presence of uranium.

- Uranium solids are found on the surface and in the internal cavities of both sodalite and amorphous phases of NAS,

- Uranium solids may be physically trapped within the internal structures of both amorphous and sodalite phases,

- Not all uranium solids bound on NAS surfaces are easily removed by agitation with DI water,

- The order of uranium loading during syntheis in the unwashed NAS solid phases are sodalite>amorphous>>Zeolite A,

- The order of measurable uranium, which could not be leached out with water and $\mathrm{Na}_{4}$ EDTA solution and thus considered trapped inside the NAS phases, is Amorphous>sodalite>>Zeolite A.

For further studies, we recommend the following.

- Repeat synthesis and characterizations of all NAS materials in duplicate with detailed analytical characterization of NAS synthesis with and without uranium and evaluate the effect of uranium in NAS product yield.

- More studies should be done to investigate uranium solubility and solid phase formation in the presence of Silicon and Aluminum.

- Synthesis the aluminosilicates in the presence of U-235 in place of depleted uranium to enhance solid characterizations for incorporated uranium by neutron activation analysis.

- Complete NAS study with the synthesis of cancrinite with and without uranium. 
WSRC-TR-2002-00527, Rev. 0

Page 29 of 41

November 20, 2002

\section{APPENDIX A}

Recipes for synthesizing sodium aluminosilicates 


\section{Solution Preparation for the Synthesis of amorphous sodium aluminosilicate}

The solution used for the synthesis of the amorphous NAS phase was a reaction mixture consisting of equal volumes of solutions $\mathrm{A}$ and $\mathrm{B}$ from Tables $\mathrm{A}$ and $\mathrm{B}$ below. The resulting concentration for each reagent is summarized in Table $\mathrm{C}$ below. The reaction temperature and duration of reaction for the amorphous phase was, respectively, $40^{\circ} \mathrm{C}$ and one hour (See Table D below).

\section{Solution Preparation for the Synthesis of zeolite A based on aluminum foil and sodium carbonate}

Basis: One liter of analytical grade reagent solution.

163.27 g sodium hydroxide

$47.22 \mathrm{~g}$ of sodium carbonate mono-hydrate $(0.38 \mathrm{M})$

$46.33 \mathrm{~g}$ of aluminum foil ( $>93 \%$ purity $\left(1.7 \mathrm{M} \mathrm{Al}^{3+}\right)$ ). Standard gauge aluminum foil (See below for aluminum extraction steps) from Fisher scientific; thickness of $0.018 \mathrm{~mm}$ and width of $30.5 \mathrm{~cm}$.

$43.3 \mathrm{~g}$ of sodium silicate pentahydrate or $58.0 \mathrm{~g}$ of sodium silicate nanohydrate $(0.2 \mathrm{M}$ $\left.\mathrm{SiO}_{2}\right)$

Reaction temperature of $90{ }^{\circ} \mathrm{C}$

Reaction duration of 2 or 3 hours

1000-mL stainless steel (SS) beaker with handle

A large open glass water jar containing water up to the $500 \mathrm{~mL}$ mark and sitting on a magnetic stirrer.

\section{Extraction of Aluminum $\left(\mathrm{Al}^{3+}\right)$ from $46.33 \mathrm{~g}$ aluminum foil and Reagent dissolution steps.}

Note before: This solution preparation must be performed inside a hood and instructions should be read through first before any attempts to prepare this solution.

1. Put the SS beaker inside a large water jar containing about $400 \mathrm{ml}$ of water.

2. Dissolve the $163.27 \mathrm{~g}$ of sodium hydroxide in $\approx 600 \mathrm{~mL}$ DI water contained inside the SS beaker.

3. Dissolve the $47.22 \mathrm{~g}$ of sodium carbonate mono-hydrate in the beaker, too.

4. Put about $100 \mathrm{ml}$ of the solution from step 3 above into a $200-\mathrm{mL}$ volumetric flask

5. Dissolve the $43.3 \mathrm{~g}$ of sodium silicate pentahydrate or nanohydrate equivalent in the solution inside the $200-\mathrm{mL}$ volumetric flask.

6. Use extra solution from step3 above to bring the solution level in the 200-mL flask to mark. Label and save this solution as "Silicate/carbonate solution".

7. Based on the purity level of the aluminum foil, weight out exactly $46.33 \mathrm{~g}$ of the foil.

8. Use a scissors to cut the aluminum foil into three batches of aluminum strips not more than $1 \mathrm{~cm}$ by $10 \mathrm{~cm}$. 
9. Ensure that SS beaker is inside the glass water jar and turn the magnetic stirrer on.

10. While the contents of the SS beaker is stirring, carefully introduce strips of the aluminum foil into the SS beaker from the first batch of aluminum strips.

11. After dissolving the aluminum strips from the first batch, add about $100 \mathrm{ml}$ of DI water to the SS beaker.

12. Be careful, the temperature of the caustic solution inside the beaker can be as high as $160{ }^{\circ} \mathrm{C}$.

13. Repeat steps 10 and 11 above with the second and third batches of the aluminum foil strips.

14. After dissolving all the aluminum strips, allow the solution to cool down to about $50^{\circ} \mathrm{C}$.

15. Adjust the volume of the caustic solution to about $750 \mathrm{ml}$ by adding DI. (Note the color of the solution is black because of carbon black impurities in the aluminum foil).

16. Use a pre-wetted 0.45 -micron nylon or Teflon filter (1-liter capacity filter) to filter the caustic aluminum solution.

(The filtrate should be optically clear and contain no traces of carbon black).

17. The filtrate should be put in a volumetric flask and its total volume adjusted to 800 $\mathrm{ml}$ with distilled water for ordinary zeolite synthesis or else to $795 \mathrm{ml}$ for zeolite synthesis in the presence of uranium. This requires the addition of extra $5 \mathrm{~mL}$ of uranium stock solution to give a uranium solution of $50 \mathrm{mg} / \mathrm{L}$

18. Deliver this final $800 \mathrm{ml}$ (or $795 \mathrm{ml}$ in the case of zeolite synthesis with uranium) caustic solution into the reactor vessel and bring the temperature of the solution to 90 ${ }^{\circ} \mathrm{C}$. The reflux condenser may be used here to prevent the loss of water mass.

19. Deliver the solution from step 6 above $(200 \mathrm{ml}$ silicate solution) into a separate reaction vessel and bring its temperature to exactly $90{ }^{\circ} \mathrm{C}$ (prevent loss of water mass).

20. When both solutions have attained the $90{ }^{\circ} \mathrm{C}$ temperature carefully put the $200-\mathrm{mL}$ silicate solution into the reactor, already containing the caustic solution at $90^{\circ} \mathrm{C}$.

21. Timing for the reaction duration begins right after mixing the two solutions above.

22. If this zeolite synthesis requires the introduction of uranium into the reaction mixture, the 5-mL uranium stock solution is introduced in step 18 above along with now 795 mL caustic solution.

23. The reaction duration is between 2 and 4 hours; we suggest 2 hours.

24. Intermittent sampling should be done every 10 minutes, which gives a total of 12 samples.

25. During each sampling, about 5 to $7 \mathrm{ml}$ of the liquid is collected using a syringe momentarily inserted into the sampling port. A 0.25 or 0.45 -micron filter disc inserted onto the syringe is used to separate the liquid from the solid fraction.

26. The filtrates are submitted for uranium and silica analysis. 
WSRC-TR-2002-00527, Rev. 0

Page 32 of 41

November 20, 2002

$\underline{\text { Solution A }}$

\begin{tabular}{|l|l|l|l|l|}
\hline Compound & $\begin{array}{l}\text { Concentration, } \\
\text { moles/Liter }\end{array}$ & \%Purity & FW & Amount used per Liter of DI \\
\hline $\mathrm{NaOH}$ & 4.0 & 98 & 40 & $(40 * 4) / 0.98=\mathbf{1 6 3 . 2 7}$ g/ Liter \\
\hline $\mathrm{NaNO}_{3}$ & 2.0 & 99 & 84.99 & $(84.99 * 2) / 0.99=\mathbf{1 7 1 . 7 0}$ / Liter \\
\hline $\mathrm{NaNO}_{2}$ & 2.0 & 99.5 & 69 & $(69 * 2.0) / 0.995=138.69$ g $/$ Liter \\
\hline $\mathrm{Al}\left(\mathrm{NO}_{3}\right)_{3} .9 \mathrm{H}_{2} \mathrm{O}$ & 0.94 & 98 & 375.14 & $(375.14 * 0.94) / 0.98=\mathbf{3 5 9 . 8 3} \mathbf{~ g} /$ Liter \\
\hline
\end{tabular}

Solution B

\begin{tabular}{|c|c|c|c|c|}
\hline Compound & $\begin{array}{l}\text { Concentration } \\
\text { moles/Liter }\end{array}$ & \%Purity & FW & Amount required per Liter of DI \\
\hline $\mathrm{NaOH}$ & 4.0 & 98 & 40 & $(40 * 4) / 0.98=\mathbf{1 6 3 . 2 7}$ g/ Liter \\
\hline $\mathrm{Na}_{2} \mathrm{OSiO}_{2} .5 \mathrm{H}_{2} \mathrm{O}$ & 0.75 & 97 & 212.1 & $(212.1 * 0.75) / 0.97=\mathbf{1 6 3 . 9 9} \mathbf{g} /$ Liter \\
\hline
\end{tabular}

Solution C (50\% A: 50\% B solution)

\begin{tabular}{|l|l|}
\hline Compound & Concentration, moles/Liter \\
\hline $\mathrm{NaOH}$ & 4.0 \\
\hline $\mathrm{NaNO}_{3}$ & 1.0 \\
\hline $\mathrm{NaNO}_{2}$ & 1.0 \\
\hline $\mathrm{Al}_{2}\left(\mathrm{NO}_{3}\right)_{3} \cdot 9 \mathrm{H}_{2} \mathrm{O}$ & 0.47 \\
\hline $\mathrm{Na}_{2} \mathrm{OSiO}_{2} \cdot 5 \mathrm{H}_{2} \mathrm{O}$ & 0.38 \\
\hline
\end{tabular}

Table A 1. Combined synthetic conditions for all NAS phases

\begin{tabular}{|l|l|l|l|l|}
\hline & Amorphous & Zeolite A & Zeolite 6012 & Sodalite \\
\hline Supersaturated solution & $\mathrm{C}$ & Others & Others & $\mathrm{C}$ \\
\hline Synthesis temperature, ${ }^{\circ} \mathrm{C}$ & 40 & 90 & 60 & 80 \\
\hline Duration of reaction, $\mathrm{h}$ & $\leq 1.0$ & $2-4$ & 12 & $\leq 1.5$ \\
\hline
\end{tabular}




\section{Solution Preparation for the Synthesis of Zeolite A 6012} (non-carbonate formulation).

Basis: One liter of analytical grade reagents.

65.0 g Sodium silicate solution $(14 \% \mathrm{NaOH}$ and $27 \% \mathrm{SiO} 2$, Aldrich, cat. \# 33,844-3)

57.42 g Sodium Aluminate hydrate (54\% Al2O3)

188 g Sodium Hydroxide ( $~ 99 \%$ purity)

148.5 Highly pure distilled water

$5 \mathrm{ml}$ of uranium nitrate stock solution (equivalent to $50 \mathrm{mg} / \mathrm{L}$ total uranium).

Temperature $=60^{\circ} \mathrm{C}$.

Batch reaction time $=12$ hours

\section{Reagent dissolution steps}

1. Completely dissolve the $188 \mathrm{~g}$ of $\mathrm{NaOH}$ first in $700 \mathrm{ml}$ of DI water (let solution cool to room temperature)

2. Completely dissolve the $57.42 \mathrm{~g}$ of Sodium Aluminate hydrate slowly in the caustic solution from Step 1.

3. Put solution from step 2 above into the reactor.

4. Carefully deliver the $5 \mathrm{ml}$ of uranium nitrate stock solution into the reactor while the stirring mechanism is on at $400 \mathrm{rpm}$ and temperature of the mixture is raised to $60^{\circ} \mathrm{C}$. This step may depend on whether uranium is part of the synthesis or not. If uranium is not part of the synthesis introduce instead $5 \mathrm{ml}$ of DI water in place of uranium solution.

5. Add an extra $208.24 \mathrm{ml}$ of DI water into the reactor and wait for the temperature to reach $60^{\circ} \mathrm{C}$, again.

6. In a separate reaction vessel deliver exactly $46.76 \mathrm{ml}(65.0 \mathrm{~g})$ of Sodium silicate hydrate and warm it up to 60' C.

7. Rinse the container for the Sodium silicate hydrate in section 6 with $40 \mathrm{ml}$ DI and put into the same separate reaction vessel as in section 6 above.

8. Let solution from steps 1 through 5 above be considered here as solution 1 (S1) and solution from steps 6 and 7 above as solution 2 (S2).

9. When both solutions are at $60^{\circ} \mathrm{C}$, mix solution $\mathrm{S} 1$ and $\mathrm{S} 2$ slowly with agitation (400 $\mathrm{rpm})$ to start the 12 hours reaction time.

10. Note: The solution volume is now $1000 \mathrm{~mL}$.

Initially, the resulting solution after stirring for some time is optically clear. The above recipe was used for the synthesis of zeolite without sodium carbonate solution. Another form of stable zeolite A can also be produced from the old version of making zeolite A, 
based on aluminum foil as described above. Although, this time the sodium carbonate is completely omitted (See SEM photos).

\section{Solution Preparation for the Synthesis of sodalite aluminosilicate.}

The solution used for the synthesis of the amorphous NAS phase was a reaction mixture consisting of equal volumes of solutions A and B from Tables A and B above. The resulting concentration for each reagent is summarized in Table $\mathrm{C}$ above. The reaction temperature and duration of reaction for the sodalite phase was, respectively, $80{ }^{\circ} \mathrm{C}$ and less than or equal to one and a half-hour (See Table D above).

\section{Reference Curve Solution}

In all the cases involving the generating of uranium reference curves, the same solutions, as described above, were used without the introduction of the silicate reagents. The ionic strength of the resulting reference curve solution, designed to contain no silicate solution, was adjusted with equimolar concentration of sodium hydroxide solution.

Table A 2. Final reagent concentrations for the synthesis of all NAS

\begin{tabular}{|c|c|c|c|c|}
\hline Reagents & $\begin{array}{l}\text { Amorphous } \\
\text { (moles/Liter) }\end{array}$ & $\begin{array}{l}\text { Zeolite A } \\
\text { (moles/Liter) }\end{array}$ & $\begin{array}{l}\text { Zeolite A } 6012 \\
\text { (moles/Liter) }\end{array}$ & $\begin{array}{l}\text { Sodalite, } \\
\text { (moles/Liter) }\end{array}$ \\
\hline $\mathrm{NaOH}$ & 4.0 & 4.0 & 4.7 & 4.0 \\
\hline $\begin{array}{l}\mathrm{NaNO}_{3} \\
\mathrm{NaNO}_{2} \\
\mathrm{Al}\left(\mathrm{NO}_{3}\right)_{3} .9 \mathrm{H}_{2} \mathrm{O}\end{array}$ & $\begin{array}{l}1.0 \\
1.0 \\
0.47\end{array}$ & & & $\begin{array}{l}1.0 \\
1.0 \\
0.47\end{array}$ \\
\hline $\mathrm{NA}_{2} \mathrm{SO}_{3} .5 \mathrm{H}_{2} \mathrm{O}$ & 0.38 & $0.2 \mathrm{SiO}_{2}(43.3 \mathrm{~g})$ & & 0.38 \\
\hline $\mathrm{Na}_{2} \mathrm{CO}_{3} \cdot \mathrm{H}_{2} \mathrm{O}$ & & 0.38 & & \\
\hline $\begin{array}{l}46.33 \text { g Al foil } \\
\text { (93\% purity) }\end{array}$ & & $1.7\left(\mathrm{Al}^{3+}\right)$ & & \\
\hline $\begin{array}{l}\text { Sodium silicate } \\
\text { solution }(14 \% \mathrm{NaOH} \\
\text { and } 27 \% \mathrm{SiO2})\end{array}$ & & & $0.29 \mathrm{SiO}_{2}(65.0 \mathrm{~g})$ & \\
\hline $\begin{array}{l}\text { Sodium aluminate } \\
\text { hydrate }\left(54 \% \quad \mathrm{Al}_{2} \mathrm{O}_{3}\right)\end{array}$ & & & $0.29 \mathrm{Al}^{3+}(57.42 \mathrm{~g})$ & \\
\hline Basis & 1.0 & 1.0 & 1.0 & 1.0 \\
\hline
\end{tabular}


WSRC-TR-2002-00527, Rev. 0

Page 35 of 41

November 20, 2002

\section{ATTACHMENT B}

Sodium aluminosilicate structure confirmation data: Scanning electron microscopy photographs for amorphous, zeolite A and sodalite. 
WSRC-TR-2002-00527, Rev. 0

Page 36 of 41

November 20, 2002
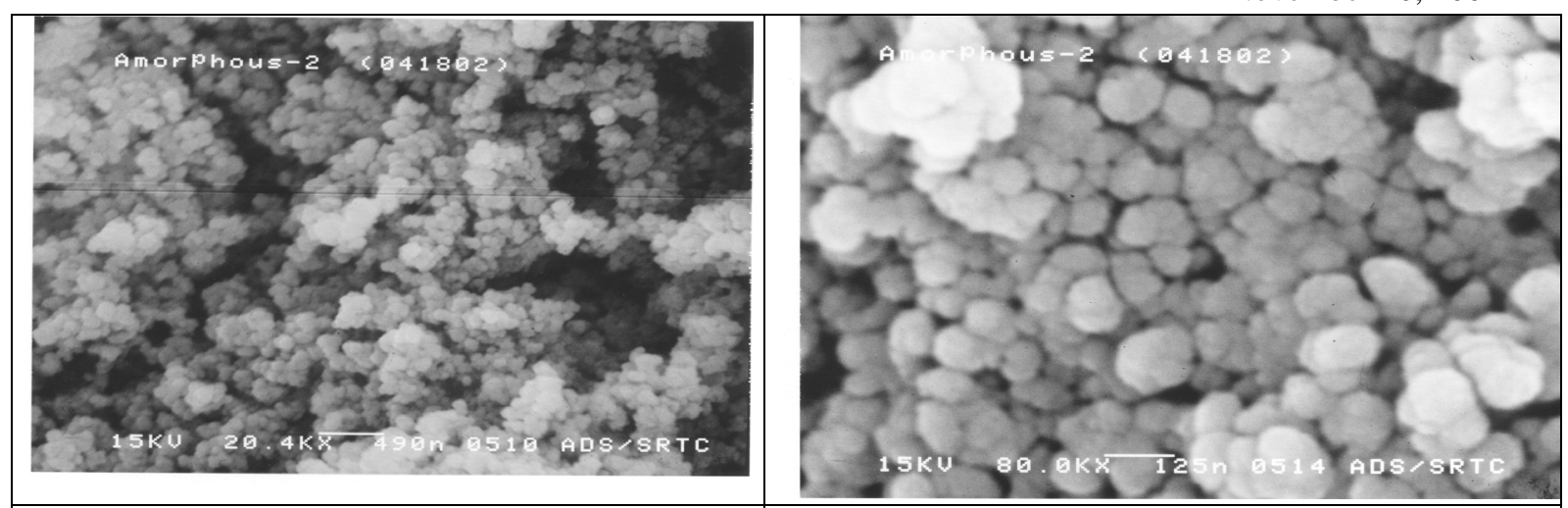

Amorphous phase at 20,000 X magnification

Amorphous phase at $80,000 \mathrm{X}$ magnification
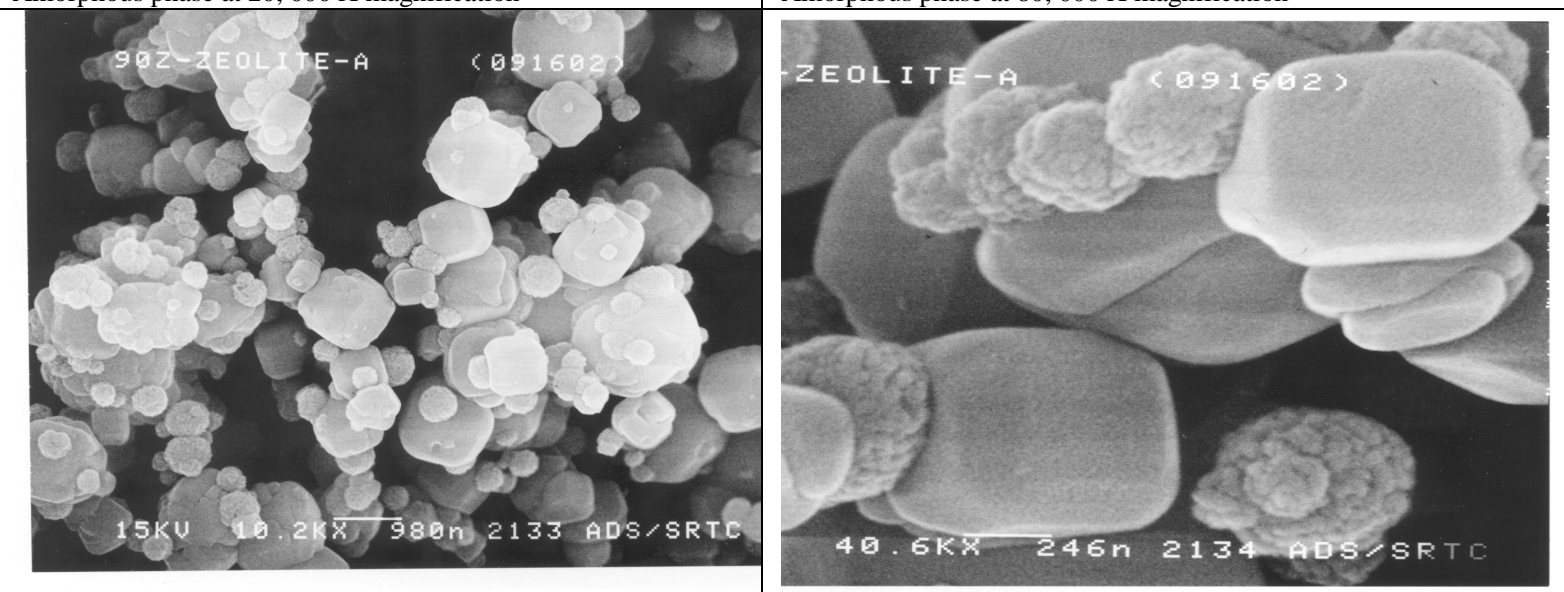

Zeolite A old formulation at 10, $000 \mathrm{X}$ magnification

Zeolite A old formulation at 40, $000 \mathrm{X}$ magnification

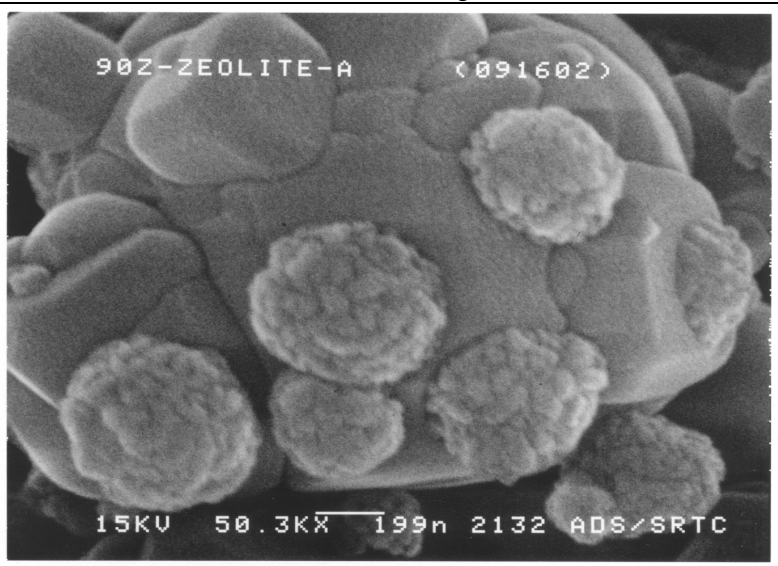

Zeolite A old formulation at 50, $000 \mathrm{X}$ magnification 
WSRC-TR-2002-00527, Rev. 0

Page 37 of 41

November 20, 2002

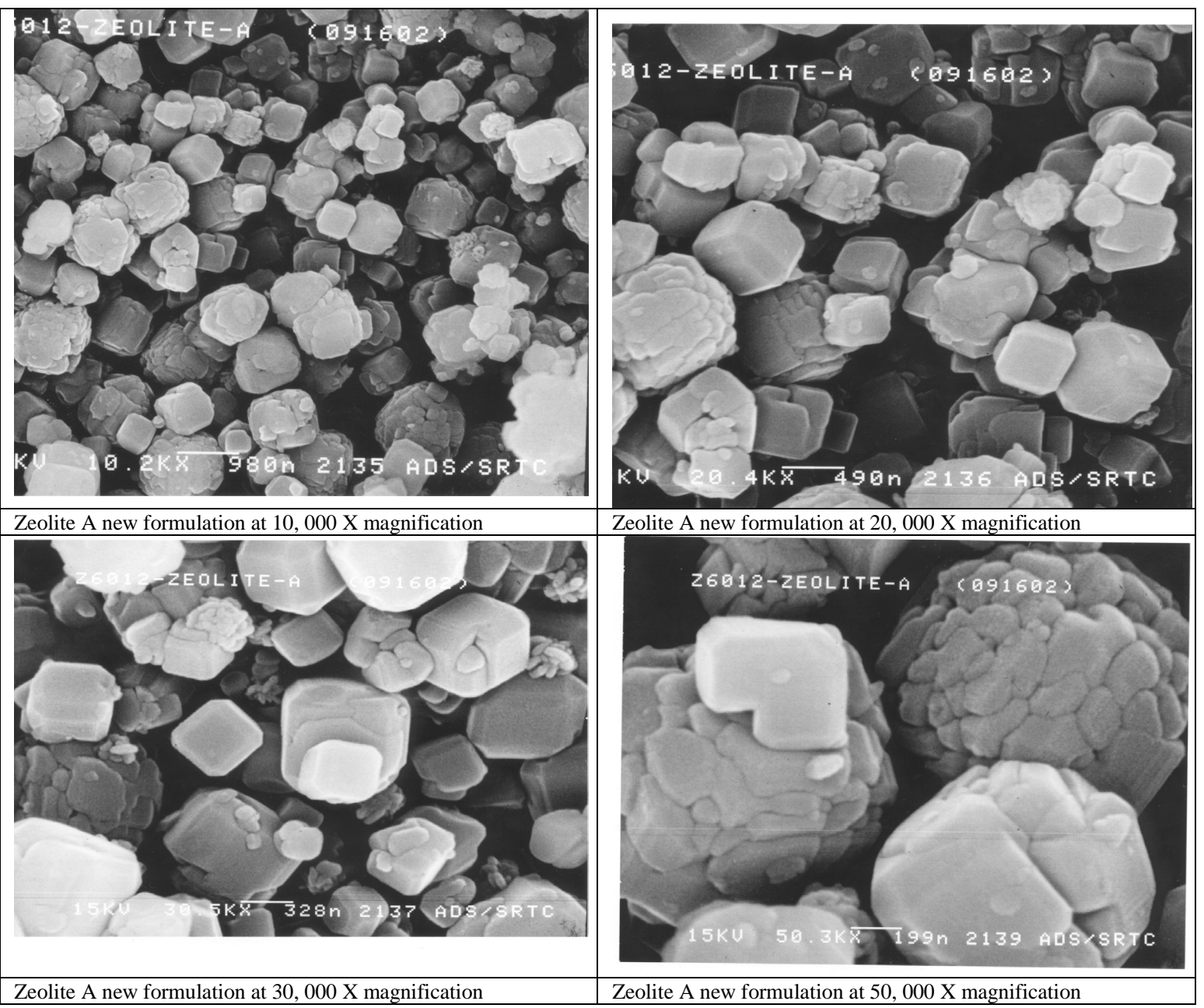


WSRC-TR-2002-00527, Rev. 0

Page 38 of 41

November 20, 2002

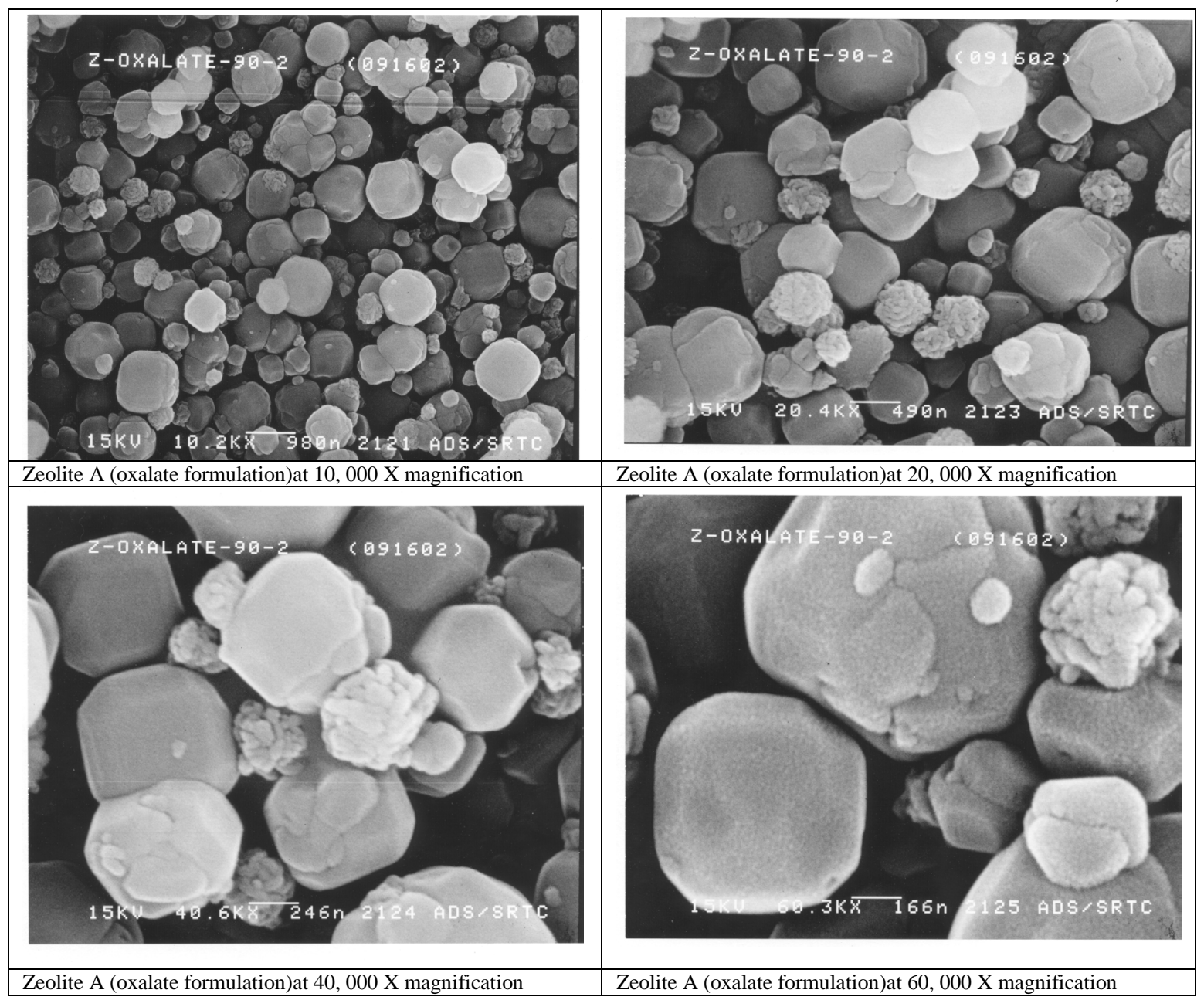


WSRC-TR-2002-00527, Rev. 0

Page 39 of 41

November 20, 2002

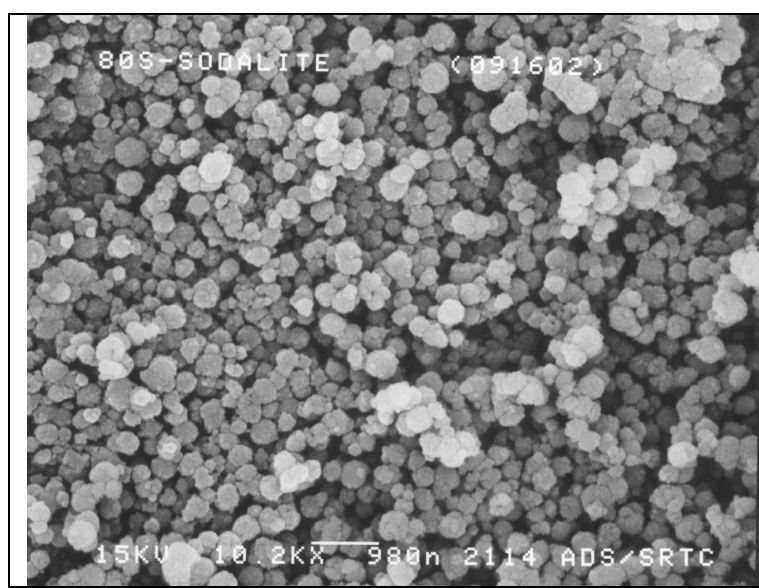

Sodalite at 10,000 X magnification

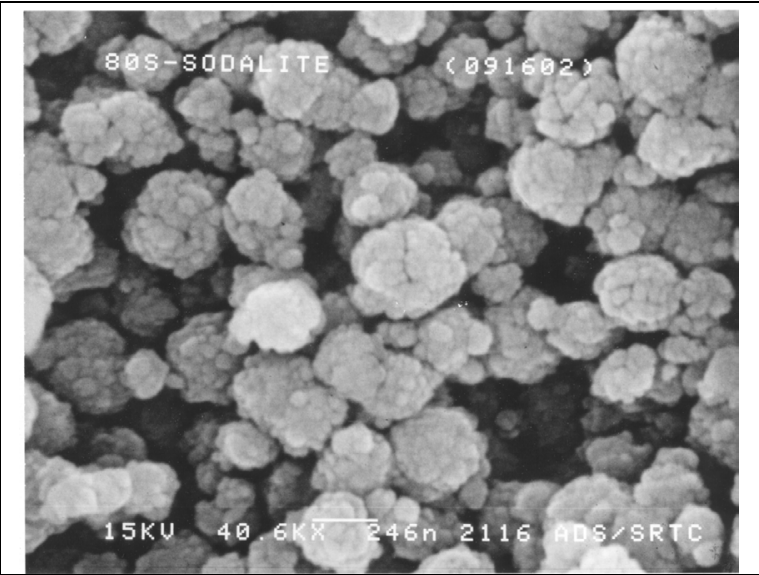

Sodalite at 40,000 X magnification

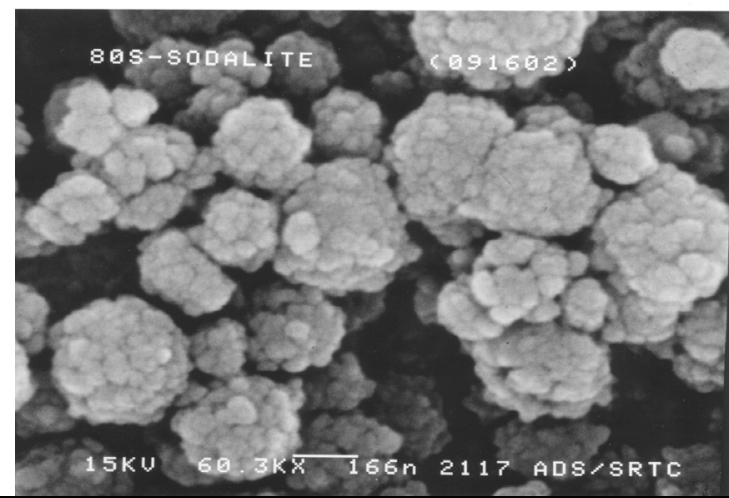

Sodalite at $60,000 \mathrm{X}$ magnification

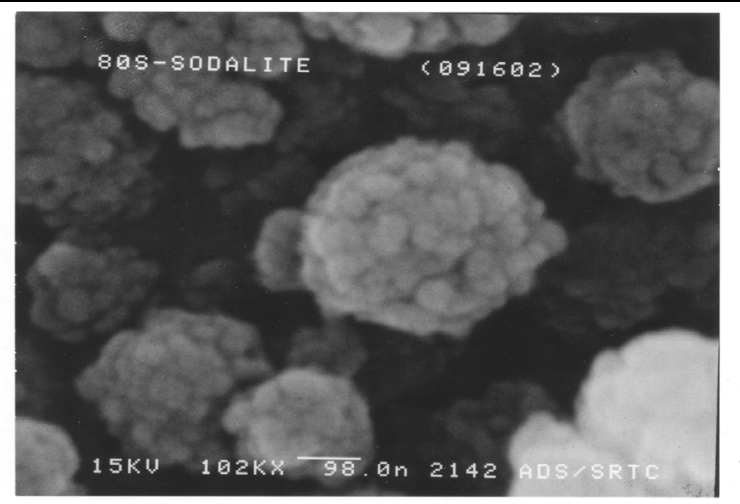

Sodalite at $102,000 \mathrm{X}$ magnification 


\subsection{QUALITY ASSURANCE}

This study fulfills the activity defined in "Task Technical and Quality Assurance Plan for the Evaluation of Uranium Co-precipitation with Sodium Aluminosilicate Structures," WSRC-RP-2001-01096, Rev.0, Dec. 13,2001. Data obtained from this study reside as records in WSRC-NB-2002-00032.

\subsection{ACKNOWLEDGEMENTS}

The authors thank Analytical Development Section personnel, in particular, B. Boyce, M. Malek and J. Hart for performing uranium and other metal analysis. Special thanks are also due DR. F. Fondeur and S. McCollum for all their efforts in Infrared characterization of NAS solids. We also thank M. S. Blume for assistance in completing this aluminosilicate synthesis and characterization.

\subsection{REFERENCES}

${ }^{1}$ W.R. Wilmarth, S. D. Fink, D.T. Hobbs, and M.S Hay, "Characterization and Dissolution Studies of Samples from the 242-16H Gravity Line”, WSRC-TR-97-0326, October 16, 1997.

${ }^{2}$ W.R. Wilmarth, D.D. Walker, S. D. Fink, "Sodium Aluminosilicate Formation in Tank 43H Simulant", WSRC-TR97-00389, November 15,1997.

${ }^{3}$ D.T. Hobbs and T. B. Edwards, "Solubility of uranium in alkaline salt solutions", WSRC-TR-94-454, March 29, 1994.

${ }^{4}$ Duff, M. C., Hunter, D. B. and L. Oji. "Characterization of Uranium Solids Precipitated with Sodium Aluminosilicates”, WSRC-TR-2002-00510, Nov. 10, 2002.

${ }^{5}$ Kali Zhen, Andrea R. Gerson, Jonas Addai-Mensah and Roger St. C Smart, "The influence of sodium carbonate on sodium aluminosilicate crystallization and solubility in sodium aluminate solutions", Journal of Crystal Growth 171 (1997)197-298.

${ }^{6} \mathrm{~V}$. Volkovich et al, "vibrational spectra of alkali metal uranates" Vibrational spectroscopy 17,(1998) 83-91.

7 Peter C. Burns and Robert Finch, "Uranium: Mineralogy, Geochemistry and the Environment", pages 535-549.

${ }^{8}$ R. A. Peterson and R. A. Pierce, "Sodium Diuranate and Sodium Alumniosilicate Precipitation Testing Results", WSRC-TR-2000-00156, May 15, 2000. 